\title{
Optimising mechanical ventilation through model-based methods and automation
}

Sophie E. Morton ${ }^{1 *}$

Jennifer L. Knopp ${ }^{1}$

J. Geoffrey Chase ${ }^{1}$

Paul Docherty ${ }^{1}$

Sarah L. Howe ${ }^{1}$

Knut Möller ${ }^{2}$

Geoffrey M. Shaw ${ }^{3}$

Merryn Tawhai ${ }^{4}$ sophie.morton@pg.canterbury.ac.nz

jennifer.knopp@canterbury.ac.nz

geoff.chase@canterbury.ac.nz

paul.docherty@canterbury.ac.nz

sarah.howe@pg.canterbury.ac.nz

moe@hs-furtwangen.de

geoff.shaw@cdhb.health.nz

m.tawhai@auckland.ac.nz

${ }^{1}$ Department of Mechanical Engineering, University of Canterbury, New Zealand

${ }^{2}$ Institute of Technical Medicine, Furtwangen University, Villingen-Schwenningen, Germany

${ }^{3}$ Department of Intensive Care, Christchurch Hospital, Christchurch, New Zealand

${ }^{4}$ Auckland Bioengineering Institute, University of Auckland, Auckland, New Zealand

*Corresponding Author, Phone: +64 33692229 


\section{Abstract}

Mechanical ventilation (MV) is a core life-support therapy for patients suffering from respiratory failure or acute respiratory distress syndrome (ARDS). Respiratory failure is a secondary outcome of a range of injuries and diseases, and results in almost half of all intensive care unit (ICU) patients receiving some form of $\mathrm{MV}$. Funding the increasing demand for ICU is a major issue and $\mathrm{MV}$, in particular, can double the cost per day due to significant patient variability, over-sedation, and the large amount of clinician time required for patient management. Reducing cost in this area requires both a decrease in the average duration of MV by improving care, and a reduction in clinical workload. Both could be achieved by safely automating all or part of MV care via model-based dynamic systems modelling and control methods are ideally suited to address these problems.

This paper presents common lung models, and provides a vision for a more automated future and explores predictive capacity of some current models. This vision includes the use of model-based methods to gain real-time insight to patient condition, improve safety through the forward prediction of outcomes to changes in MV, and develop virtual patients for in-silico design and testing of clinical protocols. Finally, the use of dynamic systems models and system identification to guide therapy for improved personalised control of oxygenation and MV therapy in the ICU will be considered. Such methods are a major part of the future of medicine, which includes greater personalisation and predictive capacity to both optimise care and reduce costs. This review thus presents the state of the art in how dynamic systems and control methods can be applied to transform this core area of ICU medicine.

Keywords: Mechanical ventilation; automation; in-silico; virtual patients, PEEP 


\section{Introduction}

\subsection{Mechanical ventilation}

Mechanical ventilation (MV) is a core life-support therapy for patients suffering from respiratory failure or acute respiratory distress syndrome (ARDS) (de Matos et al., 2012; Girard \& Bernard, 2007; Herridge et al., 2003; Lorx et al., 2010; Petrucci \& De Feo, 2013; Slutsky, 1993; Slutsky \& Tremblay, 1998; Sundaresan et al., 2009). Respiratory failure is a secondary outcome of a range of injuries and diseases, resulting in $30 \%-50 \%$ of intensive care unit (ICU) patients receiving some form of MV (Dasta, McLaughlin, Mody, \& Piech, 2005; Metnitz et al., 2009). While improvements in therapy have achieved reduced mortality rates in ventilated patients since 1995 (Maca et al., 2017), the variability and severity of condition makes care difficult and thus continues to result in an overall mortality rate of 30.5\% (Wunsch et al., 2010), where the sub-group diagnosed with ARDS have a mortality rate of $45 \%$ (Maca et al., 2017). Thus, MV is a common therapy operating at the forefront of life support and preservation in the ICU. This vision paper will focus on applications of conventional MV.

The primary issue facing healthcare sectors is funding for increasing demand. Intensive care is one of the most expensive hospital departments and MV, in particular, is an expensive treatment due to patient variability and the resulting over-sedation, and the large amount of clinician time required (Cohen \& Booth, 1994; Dasta et al., 2005). In fact, MV doubles the cost of an ICU stay (Dasta et al., 2005). Reducing the cost of this expensive therapy requires both a decrease in the average duration of MV by improving care, and a reduction in clinical workload. Both might be safely achieved by automating aspects of clinical MV care.

The ultimate aim of MV is to maintain adequate gas exchange in the alveoli. Alveolar collapse is common in ARDS, leading to seriously inhibited gas exchange and hypoxemia (Ashbaugh, Bigelow, Petty, \& Levine, 1967). To induce alveolar opening, a pressure differential must be applied physically across the lungs (Corrado \& Gorini, 2002). Historically, this differential was achieved through devices 
such as the iron lung that exposed the patient's torso to negative pressure to cause lung expansion and thus inspiration (Corrado \& Gorini, 2002). Today, positive pressure ventilators are used to treat ARDS patients (Bernard, 2005). In particular, a clinician-set inspiratory pressure is applied directly to the lungs, either invasively via an endotracheal tube (ETT) or tracheotomy, or non-invasively using a continuous positive airway pressure (CPAP) or bi-level positive airway pressure (BIPAP) mask (Brochard et al., 1995; Kárason et al., 2002). However, both positive and negative pressure ventilators can cause mechanical lung damage, known as ventilator induced lung injury (VILI), if incorrect ventilator settings are used (Albaiceta \& Blanch, 2011; Alviar et al., 2018; M. B. P. Amato et al., 1998; de Matos et al., 2012; Dirocco et al., 2006; Frederico C. Jandre, Modesto, Carvalho, \& Giannella-Neto, 2008; Kenneth Jamerson, M.D., Michael A. Weber, M.D., George L. Bakris, M.D., Björn Dahlöf, M.D., Bertram Pitt, M.D., Victor Shi, M.D., Allen Hester, Ph.D., Jitendra Gupte, M.S., Marjorie Gatlin, M.D., and Eric J. Velazquez, M.D. \& Abstract, 2017; Marini, 1994; Pinhu, Whitehead, Evans, \& Griffiths, 2003; Ranieri et al., 2011; Simonis et al., 2015; Slutsky \& Ranieri, 2014; Slutsky \& Tremblay, 1998; Terragni, Rosboch, Lisi, Viale, \& Ranieri, 2003).

Although advances in MV over the last half century have drastically improved ICU outcomes, improvements are still possible. It has been said that the future of medicine is predictive, personalised, preventative, and participatory (Auffray, Charron, \& Hood, 2010; Flores, Glusman, Brogaard, Price, \& Hood, 2013; Sobradillo, Pozo, \& Agustí, 2011). There is thus scope for, at the very least, advances in prediction and personalisation to optimise care and prevent avoidable lung injury.

\subsection{Ventilator-induced lung injury}

Ventilation strategies such as ARDSnet among others (Briel et al., 2010; Brower et al., 2000, 2004; Deans et al., 2005; Major, Shaw, \& Chase, 2018; M. O. Meade, Cook, Arabi, et al., 2008; Mercat et al., 2008; Nieman et al., 2017; Slutsky \& Ranieri, 2000) tend to follow a set protocol and are not patient- 
specific. However, as acute respiratory failure is a secondary outcome of a range of diseases, applied MV will have very different pressure-flow outcomes in different patients for the same ventilator settings. Sub-optimal settings can lead to several types of VILI (M. B. P. Amato et al., 1998; Brower et al., 2000; Hodgson et al., 2011; M. O. Meade, Cook, Arabi, et al., 2008; Slutsky \& Tremblay, 1998; Valentini, Aquino-Esperanza, Bonelli, \& Maskin, 2014), including alveolar-capillary lesions, alterations in permeability, oedema, and others, all of which hinder recovery and thus increase the length and cost of MV (M. B. P. Amato et al., 1998). Hence, intra- and inter-patient heterogeneity and variability over time makes it difficult to select ventilator settings to optimise oxygenation and gas exchange while minimising VILI (Garcia et al., 2006).

The mechanics of, and strategies for, preventing VILI are contentious (Major et al., 2018). Historically, it has been assumed VILI is caused by either excessive global pressure (barotrauma) or excessive volume (volutrauma) in a ventilation mode dependent manner. For example, in pressure controlled ventilation (PCV), pressure is the controlled variable and volume delivered is dependent on lung elastance, thus volutrauma is the risk. The converse is true for volume controlled ventilation (VCV), where volume delivery is the controlled variable, and dependent pressure makes barotrauma a possible outcome. However, such an approach is potentially over-simplified, and the mechanics of VILI are likely much more complex and patient- and/or breath-specific. Studies have recommended that both inspiratory plateau pressure and tidal volume should be limited as both barotrauma and volutrauma can occur within a given ventilation mode (Hager, Krishnan, Hayden, \& Brower, 2005).

More recent research has cast light on mechanisms of injury and strategies for mitigation of VILI. Dreyfuss and Saumon (Dreyfuss \& Saumon, 1998) postulated that alveolar strain due to the transpulmonary pressure gradient could cause injury (Nieman et al., 2018), which was later confirmed (Mols, Priebe, \& Guttmann, 2006). In addition, closed alveoli can be subjected to very high levels of shear stress when exposed to the same pressures as adjacent open healthy alveoli (Mols et al., 2006). 
Excessive shear stress can be mitigated using lung protective strategies (M. B. P. Amato et al., 1998; Brower et al., 2000; Donahoe, 2011; Laufer et al., 2017; M. O. Meade, Cook, Griffith, et al., 2008; Petrucci \& De Feo, 2013; Pintado et al., 2013; Sundaresan \& Chase, 2012), such as the use of lower tidal volumes, personalised PEEP, and moderating driving pressure (M. B. P. Amato et al., 2015; Brower et al., 2000, 2004; Futier et al., 2013; Girard \& Bernard, 2007; Iglesias et al., 2008; Jobe, 2009; M. O. Meade, Cook, Arabi, et al., 2008; Mercat et al., 2008; Nieman et al., 2018; Petrucci \& De Feo, 2013; Zick et al., 2013).

\subsection{Lung protective strategies and recruitment manoeuvres}

Lung protective strategies have improved patient outcomes by reducing VILI and improving oxygenation (M. Amato, Barbas, Medeiros, Magaldi, \& Schettino, 1998). This improvement has, in turn, resulted in reduced time on MV and thus a reduced ICU cost (Dasta et al., 2005). Recruitment manoeuvres when performed safely can also be an effective way of increasing and maintaining alveolar recruitment (Bates \& Irvin, 2002; Dyhr, Laursen, \& Larsson, 2002; Gattinoni, Carlesso, Brazzi, \& Caironi, 2010; Hess, 2015; Spieth \& Gama de Abreu, 2012). However, if performed poorly, RMs can expose patients to an increased risk of lung injury due to heterogeneity in lung and patient condition, and their response to care.

To avoid injury and to enhance recovery, recruitment of closed lung alveoli is desirable. Alveoli may collapse due to disease or injury (Mols et al., 2006), and recruitment is often achieved by applying tidal volume (Crotti et al., 2001) and PEEP to prevent derecruitment during expiration (Kacmarek et al., 2016). Alveoli have threshold opening pressures, which are typically higher than their threshold closing pressures (Sundaresan et al., 2009). Titration of PEEP through a staircase recruitment manoeuvre (RM) can open closed alveoli, improving arterial oxygenation (Brower et al., 2004) and help clinicians to determine the lowest PEEP needed to ensure sustained ventilation of recruited lung (Kacmarek et al., 2016). 
Optimal PEEP is used to prevent the repetitive opening and closing of injured alveoli, which causes atelectrauma (M. B. P. Amato et al., 1998; Briel et al., 2010; Cavalcanti et al., 2017; Gong, KruegerZiolek, Moeller, Schullcke, \& Zhao, 2015; Frederico C. Jandre et al., 2008; Jobe, 2009; Kacmarek et al., 2016; M. O. Meade, Cook, Arabi, et al., 2008; Mercat et al., 2008; Mols et al., 2006; Nieman et al., 2017; Pelosi et al., 2001; Pintado et al., 2013). Evidence suggests that titrating PEEP to the point of minimum elastance (maximum compliance), which is found using a staircase RM, could improve patient outcomes (Carvalho et al., 2007; Chiew, Pretty, Shaw, et al., 2015; Lambermont et al., 2008; Pintado et al., 2013). In this manner, the minimum elastance strategy maximises recruitment, while minimising the risk of volutrauma or barotrauma.

In a staircase RM that is carried out at the beginning of ventilation, PEEP is typically increased in steps of $2 \mathrm{cmH}_{2} \mathrm{O}$ or $4 \mathrm{cmH}_{2} \mathrm{O}$ until a set limit of plateau pressure (pressure controlled ventilation) or tidal volume (volume controlled ventilation) is reached, before being stepped down to the initial PEEP level. A first RM can be used to recruit collapsed alveoli, while maintaining recruitment of those already open. The process can be immediately repeated to titrate PEEP and determine the PEEP level where minimum elastance is achieved (Pintado et al., 2013). After this second RM is completed, a new PEEP setting can be selected (Chiew, Pretty, Shaw, et al., 2015).

The optimal RM pressure range is contentious (Cavalcanti et al., 2017; Hodgson et al., 2011; Mercat et al., 2008), as the higher pressures in an RM carry risk of barotrauma or volutrauma, where short exposures to damaging MV may reverse any improvements in patient state (Carvalho et al., 2007; Cavalcanti et al., 2017; Hodgson et al., 2011; Suarez-Sipmann et al., 2007). Thus, forward prediction of lung mechanics throughout a staircase RM would allow clinicians to manage the trade-off between the risk of barotrauma and volutrauma, while maximising the benefit of additional lung volume being recruited. Such an approach would enable safer RM application with greater insight into desired 
outcomes and potential risks.

Increases in PEEP throughout an RM also result in additional lung volume, or $V_{\text {frc }}$, due to alveolar recruitment (Dellamonica et al., 2011; Morton, Knopp, Docherty, Shaw, \& Chase, 2018; van Drunen, Chase, Chiew, Shaw, \& Desaive, 2013; Wallet et al., 2013). Determining $V_{\text {frc }}$ is often invasive, or requires imaging (Computed Tomography (CT) or Electrical Impedance Tomography (EIT)) that either cannot be carried out at the bedside (van Drunen et al., 2013) or is not available in every care unit. Model-based predictions of $V_{\text {frc }}$ across each RM step could aid PEEP optimisation, and minimise the risk of unintended volutrauma. Potentially, PEEP could even be titrated based on $V_{f r c}$ as this recruited additional lung volume is the direct goal of applying PEEP.

Due to the nature of respiratory disease (Albert et al., 2009; Bates \& Irvin, 2002; Ma \& Bates, 2010; Marini, 1994), alveoli that have been opened by an RM can collapse despite optimal PEEP settings. Therefore, multiple RMs can be required during MV (Morton, Dickson, Chase, Docherty, Howe, et al., 2018b; Stahl et al., 2006) to re-open collapsed alveoli and sustain oxygenation, along with providing a means of monitoring $V_{\text {frc }}$ (Chiew, Pretty, Shaw, et al., 2015; van Drunen et al., 2013). These RMs often involve a clinician carrying out single steps up and down in PEEP. Development of a predictive model of lung mechanics would allow this process to be optimised and automated, including monitoring of patient-specific condition and regularly optimising PEEP as the condition evolves, which would in turn reduce clinical load and potentially improve outcomes via personalised care (Morton, Dickson, Chase, Docherty, Howe, et al., 2018b).

Overall, MV is an important and widely used therapy in the ICU. Currently, most MV protocols are generalised and fail to address the heterogeneity of MV patients. Tailoring MV to patient condition is thus currently reactive, ad hoc, and variable in application. To avoid VILI, ventilator settings need to be optimised to individual patient-specific lung mechanics, and the evolving condition. Thus, there is 
a need for greater personalisation of MV. Model-based methods are ideally suited to meet these needs.

\subsection{Model-based methods}

Model-based methods offer a way of using individual patient physiology and response to MV to suggest optimal ventilator settings (Chiew, Chase, Shaw, Sundaresan, \& Desaive, 2011; Davidson et al., 2014; Docherty, Schranz, Chiew, Möller, \& Chase, 2014; Pintado et al., 2013; Szlavecz et al., 2014). In particular, models and data can be used to gain insight into lung elastance and resistance to flow. Elastance is the inverse of compliance and is a measure of lung stiffness or resistance to volumetric expansion. Elastance and resistance change depending on the lung injury or disease state. Importantly, these models can be used to quantify aspects of patient lung physiology over time, capturing a patient's time-dependent disease state as patient condition evolves. These models have the potential to enable predictive, personalised, and potentially automated, approaches to $\mathrm{MV}$, as seen successfully in glycaemic control in the ICU (Chase et al., 2010, 2011; Chase, Desaive, \& Preiser, 2016; Evans et al., 2011; Stewart et al., 2016).

This paper reviews common dynamic lung mechanics models, and provides a vision for the future of MV through the exploration of what ICU patient respiratory models must be capable of in order to be clinically useful. Such methods are a significant first step towards the personalised and predictive future of MV and medicine. 


\section{2: Vision of Future}

Better control systems engineering is essential to improve mechanical ventilation therapy. One emerging vision for the future of $\mathrm{MV}$ involves the use of models and clinical data to personalise care and guide MV therapy using the fundamental tools from the dynamic systems and control field. This vision incorporates three complementary aspects:

1) Better dynamic system models to provide improved model-based assessment of lung condition and response to $\mathrm{MV}$ at the bedside in real-time.

2) Improved system identification to make these models patient-specific and improve their predictive capacity so they can be used to safely optimise care.

Combining \#1-2 creates an ideal virtual patient, which can then be used to provide:

3) Improved, patient-specific care at the bedside using virtual patient models and methods to guide and optimise care using measured data and a clinically applied form of feedback control.

Model-based measures of lung mechanics provide additional insight at the bedside, by merging models, clinical data, and system identification to assist clinician decision making. A range of lung elastance and mechanics models have been developed (Bates, 2009; Chelucci et al., 1991; Chiew, Pretty, Docherty, et al., 2015; Guttmann et al., 1995; Sundaresan et al., 2009; van Drunen et al., 2014; Zhao, Guttmann, \& Möller, 2011) to assess lung mechanics health throughout MV. However, these models are not widely used to determine optimal patient-specific treatment, nor in automated decision support.

Real-time information would provide clinicians with immediate indicators of patient-specific condition evolution and how they are responding to treatment, beyond the current, static, snapshot of 
information available from a ventilator. Incorporation of emerging, non-invasive imaging techniques such as EIT (Balleza-Ordaz, Perez-Alday, Vargas-Luna, \& Riu, 2015; Bodenstein, David, \& Markstaller, 2009; Gong et al., 2015; Heizmann, Baumgärtner, Zhao, \& Möller, 2014; Karsten et al., 2013; Mezidi et al., 2018; Spaeth, Daume, Goebel, Wirth, \& Schumann, 2016; Zhao, Fischer, Frerichs, Müller-Lisse, \& Möller, 2012; Zhao, Steinmann, Frerichs, Guttmann, \& Möller, 2010), into predictive lung models would ensure the localised effects of many lung diseases could be better seen, and treatment could be adjusted accordingly to further optimise patient care. Currently, the most insightful imaging techniques are not available at the bedside due to physical limitations (Chase et al., 2014), which means pulmonary care and outcome is often determined solely based on limited insight from pressure-flow data available from the ventilator.

The limited data available from a ventilator gives a global, not localised idea of mechanics. If a clinician chooses to take a more conservative approach to ventilation, the heterogeneity of many lung diseases means this choice can result in under-ventilated lung regions. The combination of added imaging information with clinically relevant models would thus allow these effects to be better understood, monitored, and treated. In particular, EIT provides detailed information about regional ventilation by measuring impedance changes across electrodes attached to the skin (Balleza-Ordaz et al., 2015; Frerichs et al., 2003; Hahn, Frerichs, Kleyer, \& Heilige, 1996; Kunst et al., 2000; Sundaresan \& Chase, 2012; Zhao, Pulletz, Frerichs, Müller-Lisse, \& Möller, 2014). It has been shown to be useful in cases where volume cannot be easily determined solely through the ventilator, such as in spontaneously breathing patients (Frerichs et al., 2003; Gong et al., 2015; Riedel, Richards, \& Schibler, 2005; Zhao et al., 2018). Unlike other non-invasive imaging techniques, EIT has the ability to be used at the bedside. As the technology is developed further, higher availability of EIT in care units would allow accurate information about global and local lung ventilation to be used in conjunction with ventilator data to better guide and personalise care. 
Predictive methods can potentially be used to guide therapy for improved control. The prediction of potential respiratory mechanics at different MV settings allows more informed decisions to be made (Morton, Dickson, Chase, Docherty, Desaive, et al., 2018). Such model-based approaches have already been used in glycaemic control to improve the safety and efficacy of insulin dosing (Chase et al., 2007, 2008; Evans et al., 2011; Langdon, Docherty, Mansell, \& Chase, 2018; Lin et al., 2007; Stewart et al., 2016). For MV, it allows breath-to-breath monitoring of patient-specific condition and tailoring of PEEP and RMs to meet patient MV needs. It would allow clinicians to manage risk and reward throughout a staircase RM or other changes to MV settings. Model-based approaches could provide prediction of the additional lung volume that would be recruited and the peak inspiratory pressure that would be achieved after a PEEP change. Such an approach would provide a much better indication of the benefits and costs of potential therapeutic options than is possible with current ad-hoc approaches. Finally, small maintenance RMs could be automated to reduce clinical workload, increase the patient-specific responsiveness of care, and enable pilot investigations of automated control in this core ICU therapy (Arrøe, 1991; Chatburn, 2004; F C Jandre, Pino, Lacorte, Neves, \& GiannellaNeto, 2004; T. P. Laubscher, Frutiger, Fanconi, \& Brunner, 1996; Thomas P. Laubscher, Frutiger, Fanconi, Jutzi, \& Brunner, 1994; Sittig, Pace, Gardner, Beck, \& Morris, 1989; Tehrani, 2008b, 2008a, 2013; Tehrani \& Roum, 2008).

Another important aspect of model-based approaches, and in this vision, is their use in generating virtual patients to use in virtual trials. A fast, effective, and safe method of testing new therapy approaches is an unmet need in medicine, and virtual trials could meet this need. Virtual patients have already been successfully used in glycaemic control protocol development (Chase et al., 2010, 2011, 2016; Dickson et al., 2018; Evans et al., 2011; Mombaerts, Thomas, Signal, Desaive, \& Chase, 2015; S. Penning, Lambermont, Desaive, Pretty, \& Chase, 2014; Sophie Penning et al., 2012; Zhou, Dickson, Shaw, \& Chase, 2018). For their application to MV, existing models must first be able to be used in accurate forward predictions, and then be fully clinically validated (Chase et al., 2018). 
Achieving this vision of mechanical ventilation will require more physiologically relevant models, better system identification and improved control, three fundamental aspects of dynamic systems and control. The following three sections of this paper each cover one of these three key aspects. 


\section{Improved dynamic models and methods}

A range of models have been developed to describe lung mechanics. There is a fundamental trade-off between physiological accuracy and clinical relevance. The benefit of identifying aspects of the complexity and variability of lung physiology and lung injury or disease is currently ambiguous and thus to date, has not justified the high costs of high fidelity data collection. Currently, only airway pressure and flow rates are taken as typical practice in most ICU settings. In addition, respiratory failure is a secondary outcome to many disease or injury states, complicating the application of MV in a broad clinical cohort. In short, for a model to have clinical relevance and widespread use it needs to be structured simply enough to ensure clinical relevance and be mathematically identifiable using information readily available at the bedside (Chase et al., 2018; Chis, Banga, \& Balsa-Canto, 2011; Cobelli \& DiStefano, 1980; Docherty, Chase, Lotz, \& Desaive, 2011; Ljung, 1999; Riedlinger, Kretschmer, \& Möller, 2015; Schranz, Docherty, Chiew, Chase, \& Möller, 2012).

Two main groups of lung models exist: complex, finite element analysis (FEA) models, and variants on simpler lumped-parameter models (Ben-Tal, 2006). The complexity of FEA models allows lung and disease mechanics to be better understood. FEA models can provide scientists and clinicians with a much more thorough idea of the localised effects of clinical factors, such as patient positioning (Kelly S. Burrowes \& Tawhai, 2006), along with expected disease progression and pulmonary effects (Eom, Xu, De, \& Shi, 2010; Werner, Ehrhardt, Schmidt, \& Handels, 2009). However, for very large scale models non-identifiability or non-observability can become a limitation that may need to be overcome via new identification and statistical approaches. In addition, these models can also be too complex to identify from the type of clinical data that is typically available, and are thus not often accessible for clinical use.

Lumped parameter models generally define elastic-resistive respiratory behaviours and have a much lower physiological resolution and complexity than FEA models (Ben-Tal, 2006; Major et al., 2018). 
Alveoli and airways are often initially modelled as a balloon at the end of a pipe or similar (Bates, 2009). The simplicity of these models means they are readily accessible for use in a clinical context. More specifically, they are mathematically identifiable (Docherty et al., 2011; Ljung, 1999; Schranz et al., 2012) from available pressure and flow data at the bedside. However, their simplicity generally means that some dynamics are not captured. In particular, a key improvement to be made in lumpedparameter models would be more detailed parameterisation to enable disease evolution to be better understood.

\subsection{Finite Element Analysis Models}

A range of more complex finite element models seeking to accurately describe the true physiological behaviour of the lungs have been developed (Kelly S. Burrowes, Clark, Marcinkowski, et al., 2011; Kelly S. Burrowes \& Tawhai, 2006; Crampin et al., 2004; Ma \& Bates, 2010; Swan, Clark, \& Tawhai, 2012; Tawhai \& Bates, 2011; Tawhai \& Burrowes, 2003, 2008; Tawhai, Hoffman, \& Lin, 2009; Tawhai, Pullan, \& Hunter, 2000). These models typically use detailed scale-models of the pulmonary system produced using anatomical information from computed tomography (CT) (Tawhai \& Burrowes, 2003). Segmented lung data is fitted to a high order mesh, providing a very detailed anatomical model for simulating respiratory mechanics (Tawhai \& Bates, 2011). As these models typically have a very high computational cost and require individual CT scans for optimum accuracy, they are often not feasible for use in a clinical setting. They can also include a range of multi-scale models for various lung functions that contribute to gas exchange (K. S. Burrowes et al., 2013; K. S. Burrowes, Swan, Warren, \& Tawhai, 2008; Kelly S. Burrowes, Clark, \& Tawhai, 2011; Tawhai \& Bates, 2011; Tawhai \& Burrowes, 2008), and provide valuable information about changes in perfusion and ventilation throughout the lungs (Swan et al., 2012). They can also indicate the extent and progression of disease (Tgavalekos et al., 2005).

There is thus scope for their clinical use in better understanding perfusion and disease state in general, 
and over time for some patients. Equally, emerging simplified approximations using Bond Graph methods offers the potential to significantly increase computational speed (Safaei, Blanco, Müller, Hellevik, \& Hunter, 2018). Combined with enough data or imaging, they provide a link to bring greater detail to simpler elastic-resistive models.

\subsection{Elastic-Resistive Models}

\subsubsection{Single Compartment Model}

The simplest model of the lung is an elastic balloon at the end of a pipe. The balloon represents the distensible tissues, while the airways are modelled by the pipe (Bates, 2009). From this concept, a single compartment mathematical model is generated. Many variants on this basic model have been established (Ben-Tal, 2006). A single compartment model was pioneered in 1953, for patients capable of spontaneous breathing (Mead \& Whittenberger, 1953). This form of model describes the respiratory system as containing an elastic compliant section representing the lung, along with a resistive component representing the airways (Bates, 2009; Chelucci et al., 1991; van Drunen et al., 2014). This simple model is disproportionally effective for basic analyses. However, as it assumes that pressure increases linearly with volume increase, it neglects non-linear flow and other specific dynamics (Bates, 2009; Chiew et al., 2011; Lucangelo, Bernabè, \& Blanch, 2007).

This model includes the pressure difference $(R \dot{V}(t))$ in the lungs, and the elastic pressure $(E V(t))$ in the lungs. Assuming linear flow, it is defined (Bates, 2009):

$$
P(t)=E V(t)+R \dot{V}(t)+P_{o}
$$

Where $P$ is the inspiratory pressure delivered to the lungs $\left(\mathrm{cmH}_{2} \mathrm{O}\right), P_{o}$ is the ventilator PEEP setting $\left(\mathrm{cmH}_{2} \mathrm{O}\right), t$ is time (s), $V(t)$ is the applied volume (L), $\dot{V}(t)$ is the time-dependent flow (L/s), $E$ is the elastance $\left(\mathrm{cmH}_{2} \mathrm{O} / \mathrm{L}\right)$ and $R$ is the resistance $\left(\mathrm{cmH}_{2} \mathrm{O} / \mathrm{L}^{*} \mathrm{~s}\right)$ (van Drunen et al., 2014). 
The low number of parameters in this model means it is easily identifiable using clinically available data, along with being computationally inexpensive in its basic form. Thus, it can be widely applied in clinical settings with limited clinical data. It has thus been significantly extended.

\subsubsection{SLICE method}

The SLICE method was developed by Guttmann et al. in 1995 (Guttmann et al., 1995). Lung mechanics are often non-linear and volume dependent. These issues present a challenge when attempting to fit clinically relevant linear models to data. As a linear piecewise approximation of lung mechanics, the SLICE method splits the tidal volume into a set of 'slices' with a single resistance and single compliance value per volume 'slice'. Combining the resistance and compliance across the delivered volume 'slices' gives quasi-dynamic compliance and resistance values (Guttmann et al., 1995; Zhao et al., 2011; Zhao, Guttmann, \& Möller, 2012). To further linearise the behaviour, the Rohrer equation (Rohrer, 1925) is used to calculate the tracheal pressure (Guttmann et al., 1995), as opposed to the airway pressure. Eq. 1 is thus adapted to become:

$$
P_{\text {aw, slice }}(t)=\frac{V_{\text {slice }}(t)}{C_{k}}+\dot{V}_{\text {slice }}(t) \times R_{k}+P_{k}
$$

where $P_{a w, s l i c e}, V_{\text {slice, }}$ and $\dot{V}_{\text {slice }}$ are the pressure, volume and airway flow for a single slice, respectively (Guttmann et al., 1995). $P_{k}$ represents the pressure offset for each slice. $C_{k}$ and $R_{k}$ are the identified compliance $\left(\mathrm{L} / \mathrm{cmH}_{2} \mathrm{O}\right)$ and resistance $\left(\mathrm{cmH}_{2} \mathrm{O} * \mathrm{~s} / \mathrm{L} * \mathrm{~s}\right)$ for each slice (Zhao et al., 2011).

The adaptive slice model was developed to automate selection of the slice sizes based on a selected confidence interval of the results, thereby reducing error while maximising computational efficiency (Zhao et al., 2011). The linearisation of lung mechanics in the SLICE model, along with the additional accuracy in the adaptive form means it remains clinically identifiable, while still providing as many 
trustworthy estimates of elastance and resistance as possible (Zhao et al., 2011). However, tracheal pressure is more invasive to measure than airway pressure.

\subsubsection{Time-Varying Elastance Model}

Lung elastance is dependent on recruitment, which is a time-varying phenomena (Ma \& Bates, 2010; Massa, Allen, \& Bates, 2008). Therefore, a method to assess changes in this property throughout the progression of a disease is essential to guide therapy (Chiew et al., 2011; van Drunen et al., 2014). Dynamic lung elastance $\left(E_{d r s}\right)$ is an elastance that varies over a breath (time-varying). It is typically fit over inspiration using the single compartment model in Eq. 1. Having $E_{d r s}$ and $R_{d r s}$ fit to every breath allows the model to be used to optimise PEEP settings (Chiew, Pretty, Docherty, et al., 2015; van Drunen et al., 2014). It can also indicate the occurrence of over-distension or recruitment within the breath (van Drunen et al., 2014). Initial trials on dynamic elastance have only been carried out on fully sedated patients, therefore negating patient inspiratory effort, and were based on the single compartment model (Chiew, Pretty, Docherty, et al., 2015; van Drunen et al., 2014).

The model is defined:

$$
P(t)=E_{d r s}(t) V(t)+R_{r S} \dot{V}(t)+P E E P .
$$

Here $E_{\text {drs }}$ is an overall respiratory system elastance $\left(\mathrm{cmH}_{2} \mathrm{O} / \mathrm{L}\right)$ comprising chest wall elastance (which is treated as a constant) and lung elastance (which is assumed to change throughout inspiration (van Drunen et al., 2014)). Resistance is assumed to be a constant over a breath in this model.

Identifying time-varying elastance over a breath also enables detection and monitoring of the incidence and magnitude of asynchronies (Chiew et al., 2018; Kannangara et al., 2016). Asynchrony interrupts MV care and worsens outcomes, as it reflects poor interaction between the patient and 
ventilator (Chiew et al., 2018; Kannangara et al., 2016). Hence, the model of Eq. 3 can also be used to address and monitor this clinically important outcome, as well.

\subsubsection{Spontaneous Breathing Model}

Spontaneously breathing patients apply their own inspiratory efforts on top of a ventilator supported breathing cycle (Langdon, Docherty, Chiew, Damanhuri, \& Chase, 2015). A time-varying elastance model was developed to describe the mechanics of spontaneously breathing patients on partial assist mechanical ventilation (Chiew, Pretty, Docherty, et al., 2015). This model utilises a negative elastance component to describe patient-specific breathing efforts. The overall model is based on the single compartment model of Eq. 1 and the time-varying model of Eq. 3, but an adjusted $E_{d r s}$ value captures the additional patient effort on top of the ventilator support. The components of this adjusted $E_{d r s}$ value are defined:

$$
E_{\text {drs }}(t)=E_{\text {chest }}+E_{\text {demand }}(t)+E_{\text {lung }}(t)
$$

where $E_{d r s}$ is the overall time-varying respiratory system elastance $\left(\mathrm{cmH}_{2} \mathrm{O} / \mathrm{L}\right), E_{\text {chest }}$ is the constant elastic properties of the chest wall, $E_{\text {lung }}(t)$ is a time-varying measure of the elastic properties of the lung, or the collection of alveoli, and $E_{\text {demand }}(t)$ is the patient-specific inspiratory demand, which varies from breath-to-breath (Chiew, Pretty, Docherty, et al., 2015). Given a value for $E_{\text {chest, }}$ the net balance of $E_{\text {demand }}(t)$ and $E_{\text {lung }}(t)$ can be identified. It may be a positive or negative value as that patient may provide either inspiratory or expiratory pressure. The negative elastance accounts for patient breathing efforts separate to the airflow provided by the ventilator.

The ability of this model to accurately capture mechanics of spontaneously breathing patients without invasive measures extends the clinical ability of minimal models to enable titrating care for all ventilated patients (Chiew, Pretty, Docherty, et al., 2015). Negative elastance and area above this 
curve allows estimation of breathing effort by the patient. Finally, it lets the same model be used for sedated and spontaneous breathing MV modes.

\subsubsection{Other Elastic-Resistive Models}

A range of other elastic-resistive models have been developed (Ben-Tal, 2006). These models include those of Massa et al. (Massa et al., 2008) and Ma et al. (Ma \& Bates, 2010) which were used to define the processes of recruitment and derecruitment. Both of these models attempt to capture the specific, time-dependent processes carried out in an airway branch before extending this local model to estimate global lung behaviour based on expected distributions (Massa et al., 2008). It assumes that each branch has a critical opening and closing pressure, along with corresponding time constants (Ma \& Bates, 2010).

Abboud et al. (Abboud, Barnea, Guber, Narkiss, \& Bruderman, 1995) developed a model to capture the lung's flow-volume curve throughout forced expiration. This model was used to more thoroughly investigate the differences in lung stiffness between different lung diseases. Finally, in 2007, Lucangelo et al. adapted Eq. 1 to capture dysfunctional patient-ventilator interactions such as asynchronies, airleaks or sudden changes in patient condition (Lucangelo et al., 2007).

Each of these models is able to provide useful information about current lung response to ventilation and uses clinically-available information. However, the models lack the combination of predictive capabilities and clinical identifiability to be able to be used in determining lung mechanics during future changes in ventilation.

\subsection{Summary}

A range of models have been developed to define lung mechanics. Finite element models are too complex for bedside use in model-predictive and potentially automated care. Simple, mathematically 
identifiable models have demonstrated the ability to capture clinically relevant dynamics and lung mechanics. However, improvements in the field require the ability to predict the effect that changes in therapy will have on individual patients and cohorts as a whole, prior to making the change, which is not yet proven. 


\section{Improved system identification for both monitoring and prediction of lung mechanics}

While many pulmonary models have been developed to the point where they can accurately describe elastance and suggest a suitable PEEP level, it is a reactive, retrospective process. For more effective and patient specific treatment, models need to be able to extrapolate from past or current data to predict how the lung will respond to MV setting changes (Langdon, Docherty, Chiew, \& Chase, 2016). This predictive capability is essential for defining when and how to alter ventilator settings for optimised patient outcomes.

\subsection{Stochastic Models}

Stochastic models use distribution information about a population to predict future behaviour in an individual patient. Stochastic models have been used for predictive models of insulin sensitivity and virtual patient development to ensure safety in semi-automated glycaemic control (Chase et al., 2010, 2018, 2016). Specifically, these models have been instrumental in the STAR glycaemic control protocol (Evans et al., 2011; Stewart et al., 2016), using information from large amounts of clinical data to inform clinical decisions about future changes in insulin uptake to avoid hyperglycaemic and hypoglycaemic episodes.

However, stochastic modelling may be limited in its application for lung mechanics. Insulin sensitivity is modelled as a one-dimensional problem, either increasing or decreasing over time. More recent work has extended this variable in a model-based glycaemic control scenario to a two-dimensional variable that takes into consideration rate of change by including rate of change (Uyttendaele et al., 2018). However, for lung mechanics models, this variability is spread over a more variable and high, breath-to-breath time resolution.

Notably, the single compartment model of pulmonary mechanics $(P=E V+R Q+P E E P)$ already has two 
dimensions. However, this model lacks predictive capabilities. To allow for changes in elastance and resistance over time to be taken into account, the model needs to be of a higher dimension. A recent predictive elastance basis function model (Morton, Dickson, Chase, Docherty, Desaive, et al., 2018; Morton, Dickson, Chase, Docherty, Howe, et al., 2018a; Morton, Docherty, Dickson, \& Chase, 2018) has four identified dimensional $\left(E_{1}, E_{2}, R_{1}, R_{2}\right)$, meaning stochastic models will require extremely high data density.

\subsection{NARX Model}

Work has been done to predict lung mechanics at a high PEEP using information provided at a lower PEEP (Langdon, Docherty, Chiew, \& Chase, 2016). A non-linear autoregressive (NARX) resistance and basis function elastance model was developed from a viscoelastic form of the single compartment model (Langdon, Docherty, Chiew, \& Chase, 2016; Langdon et al., 2015). Basis functions were developed from overlapping B-spline functions of different orders (Langdon, Docherty, Chiew, \& Chase, 2016; Langdon et al., 2015; Langdon, Docherty, Chiew, Möller, \& Chase, 2016). This model successfully predicts lung behaviour at high PEEP levels using information provided at a lower PEEP setting/value. However, the basis function terms that were used cannot be explicitly linked to lung mechanics. This issue reduces the clinical utility of this particular model to be used in a virtual patient, as well as its diagnostic relevance.

\subsection{Basis Function Models}

More recently, work has been done to develop the NARX model to more explicitly link physiological mechanics to basis function terms for use in virtual patient development (Morton, Dickson, Chase, Docherty, Desaive, et al., 2018; Morton, Dickson, Chase, Docherty, Howe, et al., 2018a; Morton, Docherty, et al., 2018; Morton, Knopp, et al., 2018). Basis functions define both elastance and resistance as dependent on changes in pressure, flow, volume and time, which are all measured. 
Elastance is modelled with contributions from both distension and alveolar recruitment. These basis functions were shaped to match observed mechanical lung behaviour during inspiration and, in particular, the impact and trade-off between alveolar recruitment and distension across the full range of pressure and tidal volume (Morton, Dickson, Chase, Docherty, Desaive, et al., 2018). The constants $E_{1}$ and $E_{2}$ are identifiable from a single breath (Morton, Dickson, Chase, Docherty, Desaive, et al., 2018).

Pressure drop due to airway resistance is defined by the overall form of the Rohrer equation for endotracheal tube (ETT) resistance (Rohrer, 1925). ETT resistance makes up a significant proportion of ventilator resistance, causing a substantial pressure drop between the start of the endotracheal tube or the airway pressure and the end or the tracheal pressure (Guttmann et al., 2000; Guttmann, Eberhard, Fabry, Bertschmann, \& Wolff, 1993; Karason, Sondergaard, Lundin, Wiklund, \& Stenqvist, 2001). This drop can lead to incorrect values of pressure being used in calculations. Therefore, the resistance of the ETT is an important factor in determining a correct elastance and thus the optimal ventilator settings. While this equation does not consider some clinical considerations, such as deformation of the tube and lung secretions (Karason et al., 2001), its accuracy was high enough to achieve accurate lung mechanics predictions (Morton, Dickson, Chase, Docherty, Desaive, et al., 2018).

The overall model is thus defined:

$$
P(t)=\left(E_{1} e^{b(V(t))}+E_{2} \frac{P(t)}{60}\right) V(t)+\left(R_{1}+R_{2}|Q(t)|\right) Q(t)+P E E P
$$

where $P(t)$ is the inspiratory airway pressure $\left(\mathrm{cmH}_{2} \mathrm{O}\right), V(t)$ is the volume delivered $(\mathrm{L}), Q(t)$ is the airway flow (L/s), and PEEP is defined in units of $\mathrm{cmH}_{2} \mathrm{O} . E_{1}, b, E_{2}, R_{1}$ and $R_{2}$ are all breath-specific parameters to be determined (Morton, Dickson, Chase, Docherty, Desaive, et al., 2018). 
This model can also provide an estimation of the additional lung volume gained from each step in an RM, $V_{\text {frc. }}$ This value estimates the increased alveolar recruitment caused by increases in PEEP that lead to an increased end-expiratory lung volume, or dynamic function residual capacity (Dellamonica et al., 2011; Morton, Knopp, et al., 2018; van Drunen et al., 2013; Wallet et al., 2013). This value is often difficult to determine in a clinical setting. In particular, volume is generally defined as the integral of flow, and this is subject to drift in estimation. To remedy this issue, volume is generally zeroed at the end of expiration, and absolute volume in the lung is unknown. The final predictive model thus uses the derived $V_{\text {frc }}$ to determine the total inspired volume as such:

$$
P(t)=\left(E_{1} b^{\left(V(t)+V_{f r c}\right)}+E_{2} \frac{P(t)}{60}\right) V(t)+\left(R_{1}+R_{2}|Q(t)|\right) Q(t)+P E E P_{n+1}
$$

where identified lung mechanics from measured data at $\mathrm{PEEP}_{\mathrm{n}}$ are used to predict inspiratory pressures at PEEP ${ }_{n+1}$ before it is applied. $V_{\text {frc }}$ is estimated iteratively from PEEP $_{n}$ data using:

$$
V_{f r c}^{n}=\frac{\left(P E E P_{n+1}-P E E P_{n}\right)}{E_{1} e^{b V} f r c+E_{2} P E E P_{n+1} / 60} .
$$

For an initial proof of concept of virtual patients in MV, the model has been tested against clinical data (Morton, Dickson, Chase, Docherty, Desaive, et al., 2018). Results show low error when predicting upwards over the clinically relevant pressure range, with the model able to predict peak inspiratory pressure with less than $10 \%$ error over $90 \%$ of the range of PEEP changes up to $12 \mathrm{cmH}_{2} \mathrm{O}$. Figure 1 shows typical prediction results for a studied patient data set (Morton, Dickson, Chase, Docherty, Desaive, et al., 2018). 
PEEP of $14 \mathrm{cmH}_{2} \mathrm{O}$ to predict a PEEP of 18 $\mathrm{CmH}_{2} \mathrm{O}$

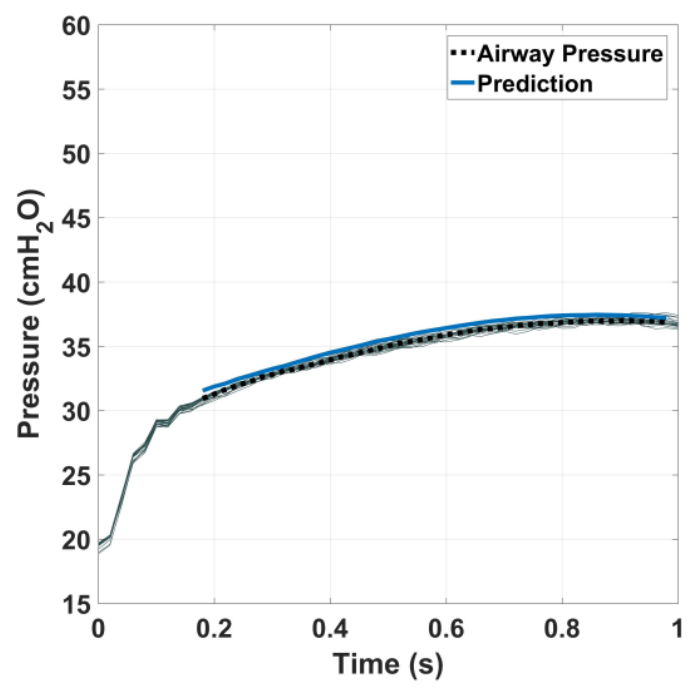

PEEP of $14 \mathrm{cmH}_{2} \mathrm{O}$ to predict a PEEP of 26 $\mathrm{cmH}_{2} \mathrm{O}$

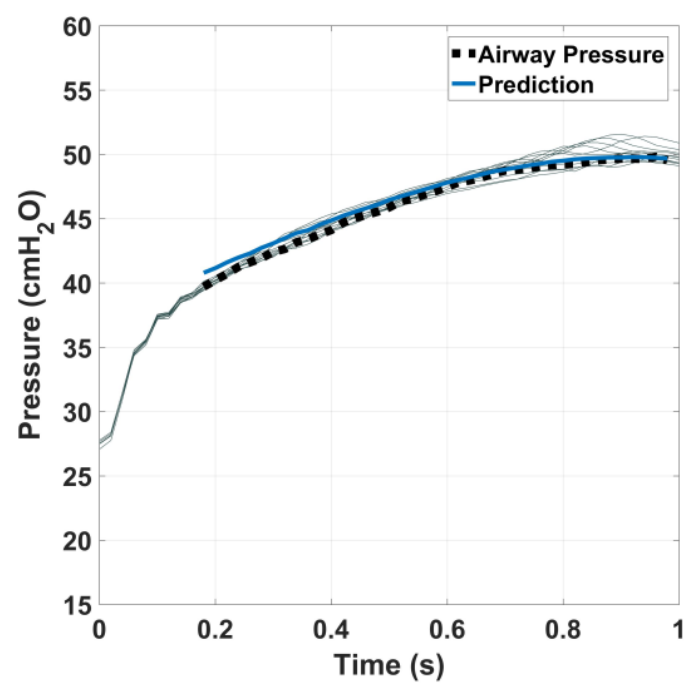

Figure 1. Typical results for prediction of pressure at a higher PEEP level using information about lung mechanics at a lower PEEP level. The solid blue line shows model prediction, the dashed black line shows the average breath at the higher PEEP level, and the light grey lines show all breaths at that PEEP level. 


\section{Stable control for clinical application}

The future of MV could utilise model-based methods to gain insight into patient condition and improve safety on a patient level through the forward prediction of outcomes, such as peak inspiratory pressure (PIP) and volume gain with a PEEP change. On a cohort level, development of virtual patient models and methods would be essential for design and efficient testing of clinical protocols with a lower patient burden (Chase et al., 2018). However, future use of such models and methods is not yet a complete concept.

\subsection{Case Study}

Figure 2 shows a case study of a possible future of MV care based on the defined vision. Model-based treatments are used throughout the entire treatment timeline. Patient-specific prediction is a key element.

In Steps 1 and 2 the patient is admitted to the care unit and intubated. At this point, pressure-flow data from the ventilator could be run through an elastic-resistive model to give the clinician an initial idea of lung mechanics and thus patient-specific lung condition. Additionally, EIT or an alternative noninvasive imaging technique would offer a better idea of heterogeneous lung effects, depending on the presenting condition. Thus, clinicians would already have far more insight and patient-specific information than in current care.

In Step 3, the first half of an initial staircase RM is carried out to recruit as many alveoli as possible, while minimising any form of VILI. Predictive methods serve two purposes at this stage. First, predicting PIP at a higher PEEP level based on current lung mechanics prior to increasing it would minimise the risk of barotrauma. The model would be generalisable enough to predict tidal volume in pressure controlled ventilation to minimise risk of volutrauma. Second, the additional lung volume to be gained from an increase in PEEP, $V_{\text {frc }}$ could also be estimated, allowing clinicians to assess the 
diminishing returns of lung volume recruitment against the risk of barotrauma or volutrauma. This $V_{f r c}$ value would significantly enhance MV care, where this trade-off cannot be evaluated today: an allnew capability. This capability would also be useful in ensuring that patients with non-recruitable lungs would not undergo a full RM, as the lack of recruitment would be indicated by plateauing of gained $V_{f r c}$. For additional insight, this could also be combined with ventilation information from EIT imaging.

In Step 4, a second RM straight after the first would also use the ability of the model to predict PIP. Lung mechanics change with recruitment, so the elastance curve changes, requiring re-fitting of the initial PEEP level. PEEP should be increased incrementally until the elastance appears to have reached a minimum. Overlaying the elastance curves from the two RMs will further confirm the range in which minimum elastance and optimal oxygenation occurs, to optimise MV settings.

Multiple smaller maintenance RMs would be - potentially automatically - carried out throughout the rest of MV care, as shown in Step 5. These RMs are used to re-recruit alveoli that have collapsed despite optimal PEEP, as well as to adjust PEEP as defined via prior RMs, as patient condition evolves. These RMs could be automated with the methods and models proposed. Development of a predictive model of lung mechanics that would allow this process to be optimised and automated, would also reduce clinical workload (Morton, Dickson, Chase, Docherty, Howe, et al., 2018b).

Finally, as patient condition improves, the patient can be weaned from ventilator support (Brochard et al., 1994; Hetland, Lindquist, \& Chlan, 2015; Lellouche et al., 2006; Marelich, 2000; Yang \& Tobin, 1992). Throughout MV, the amount of PEEP required to maintain recruitment and oxygenation should decrease and patient breathing effort increase (Branson \& Johannigman, 2009). Typically, the weaning process is not begun until patient condition has significantly improved (Alía \& Esteban, 2000; Branson, 2012; Branson \& Johannigman, 2009). In Step 6, the decrease in PEEP requirement due to improved PEEP selection could largely automate weaning, another major and difficult aspect of MV (Lellouche 
et al., 2006; Marelich, 2000; M. Meade et al., 2001), as PEEP levels fall over time and lead to a consequent reduction in ventilator dependency.

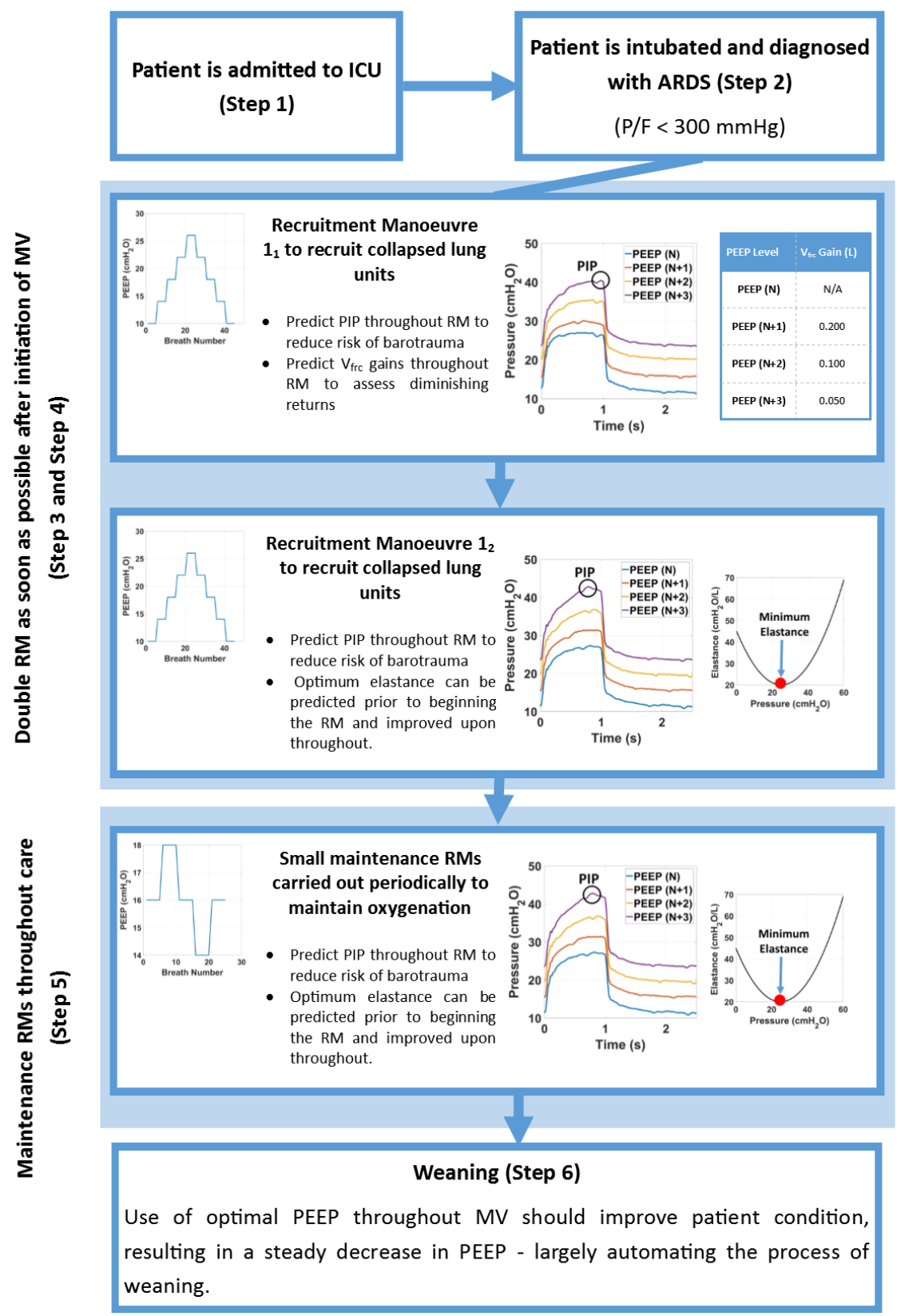

Figure 2. Case study showing anticipated patient treatment timeline in future model-based MV. 


\subsection{Virtual Patients}

Virtual patients can be developed to model the responses one may expect from an individual, or a cohort-wide scale (Chase et al., 2018, 2016). Virtual patients are used to personalise and optimise care for an individual patient by predicting response to a change in treatment prior to implementing the change. This personalisation is especially critical for ICU patients, who exhibit a great deal of variation in condition, and response to treatment (Dickson, Gunn, \& Chase, 2014). As noted, in intubated patients, personalisation would be used to predict the effects of an RM on lung elastance to minimise the risk of VILI while also maximising lung recruitment, and thus, oxygenation.

Virtual cohorts offer a method of safely and efficiently validating the effect that testing new treatments can have on a population of patients (Chase et al., 2016). A validated in-silico virtual trial platform could reduce the number of Phase II and III human trials (Chase et al., 2018). It would thus be a substantial development in mechanical ventilation, as two of the main metrics for judging an improvement in treatment across a cohort (length of mechanical ventilation and ventilator-free days (Schoenfeld \& Bernard, 2002)) are both highly skewed (Morton et al., 2017). This skew requires a large number of patients in a given clinical trial to reach statistical power (Morton et al., 2017). Capitalising on the recent FDA change to recognising virtual trials (Smalley, 2018) as a method of testing medical treatments, having virtual cohorts to test new mechanical ventilation protocols would allow the field to move forward much faster.

\subsection{Future Questions}

Improvements in model-based MV and the development of virtual patients will open up new clinical questions. Many of these questions will require the combination of model-based techniques along with imaging techniques to optimise treatment.

Assuming perfect prediction of patient response to treatment, the first of these questions is 
determining how much additional lung volume, $V_{f r c}$, is enough to consider an RM useful. While population statistics can provide general information about lung capacity in healthy individuals, the variation in patients suffering from respiratory failure means this information needs to be personalised to ensure that long-term damage is not caused to the lungs. The emergence of bedside accessible, non-invasive imaging techniques will also be increasingly essential for this application and to further improve care.

A further question may ask how optimal PEEP can be defined for patients and how best to continually assess and alter this value. While research has indicated titration of PEEP to minimum elastance results in good patient outcomes (Carvalho et al., 2007; Chiew, Pretty, Shaw, et al., 2015; Lambermont et al., 2008; Pintado et al., 2013), this approach may not hold true for all cohorts of patients. Potentially, $V_{\text {frc }}$ should also be considered in setting PEEP and other MV settings. In addition, lung mechanics often change as lung condition evolves and previously opened alveoli collapse, necessitating another RM or change in MV settings. Assuming perfect prediction of lung response throughout these RMs, their optimal frequency needs to be considered - whether additional gains in oxygenation are worth potential lung injury from changes in pressure. All of these methods will require the models and methods first, before their clinical investigation.

Ultimately MV is about maintaining blood oxygenation. Mechanical models can also be combined with gas exchange models and bedside oxygenation data to allow the effect that RMs have on oxygenation, specifically the existence of pulmonary shunt, to be better understood. Elastance and resistance values calculated from pressure and flow data offers information about the mechanical health of the lungs and subsequent alveolar recruitment. However, the success of oxygen and carbon dioxide diffusion from the alveoli to the bloodstream cannot be determined from mechanical information alone. Combining mechanical and gas exchange models would provide clinicians with more data to be able to better optimise care. 



\section{Conclusion}

The incorporation of model-based methods and automation into mechanical ventilation will aid the healthcare sector in meeting increasing demand in intensive care units. In particular, a change from more generic protocols to the use of predictive, patient-specific models will improve individual patient outcomes while also reducing clinical workload. The future use of virtual patients and cohorts will also allow new treatments and therapies to be safely and more efficiently tested, allowing for faster advancements in the field.

\section{Acknowledgements}

This work was supported by the NZ Tertiary Education Commission (TEC) fund MedTech CoRE (Centre of Research Expertise) and the NZ National Science Challenge 7, Science for Technology and Innovation

The authors also acknowledge support from the Engineering Technology-based Innovation in Medicine (eTIME) consortium grant [eTIME 318943]; the EU FP7 International Research Staff Exchange Scheme (IRSES) grant [\#PIRSES-GA-2012-318943]; 


\section{References}

Abboud, S., Barnea, O., Guber, a., Narkiss, N., \& Bruderman, I. (1995). Maximum expiratory flowvolume curve: Mathematical model and experimental results. Medical Engineering and Physics, 17(5), 332-336. http://doi.org/10.1016/1350-4533(95)97312-D

Albaiceta, G. M., \& Blanch, L. (2011). Beyond volutrauma in ARDS: the critical role of lung tissue deformation. Critical Care, 15(2), 304. http://doi.org/10.1186/cc10052

Albert, S. P., Dirocco, J. D., Allen, G. B., Bates, J. H. T., Lafollette, R., Kubiak, B. D., ... Nieman, G. F. (2009). The role of time and pressure on alveolar recruitment. Journal of Applied Physiology, 106(3), 757-765. http://doi.org/10.1152/japplphysiol.90735.2008

Alía, I., \& Esteban, A. (2000). Weaning from mechanical ventilation. Critical Care, 4(2), 72-80. http://doi.org/10.1097/ALN.0b013e3181e81074

Alviar, C. L., Miller, P. E., McAreavey, D., Katz, J. N., Lee, B., Moriyama, B., ... Morrow, D. A. (2018). Positive Pressure Ventilation in the Cardiac Intensive Care Unit. Journal of the American College of Cardiology, 72(13), 1532-1553. http://doi.org/10.1016/j.jacc.2018.06.074

Amato, M. B. P., Barbas, C. S. V., Medeiros, D. M., Magaldi, R. B., Schettino, G. P., Lorenzi-Filho, G., ... Takagaki, T. Y. (1998). Effect of a protective-ventilation strategy on mortality in the acute respiratory distress syndrome. The New England Journal of Medicine, 338(6), 347-354. http://doi.org/DOI: 10.1056/NEJM199802053380602

Amato, M. B. P., Meade, M. O., Slutsky, A. S., Brochard, L., Costa, E. L. V. V, Schoenfeld, D. a., ... Brower, R. G. (2015). Driving Pressure and Survival in the Acute Respiratory Distress Syndrome. The New England Journal of Medicine, 372(8), 747-755. http://doi.org/10.1056/NEJMsa1410639

Amato, M., Barbas, C., Medeiros, D., Magaldi, R., \& Schettino, G. (1998). Effect of a protectiveventilation strategy on mortality in the acute respiratory distress syndrome. The New England Journal of Medicine, 338(6), 347-354. http://doi.org/10.1056/NEJM199802053380602

Arrøe, M. (1991). A computerized aid in ventilating neonates. Computers in Biology and Medicine, 21(1-2), 15-21. http://doi.org/10.1016/0010-4825(91)90031-4

Ashbaugh, D. G., Bigelow, D. B., Petty, T. L., \& Levine, B. E. (1967). Acute respiratory distress in adults. The Lancet, 7(1), 60-61. http://doi.org/10.1016/S0140-6736(67)90168-7

Auffray, C., Charron, D., \& Hood, L. (2010). Predictive, preventive, personalized and participatory medicine: back to the future. Genome Medicine, 57(2). http://doi.org/doi:10.1186/gm178

Balleza-Ordaz, M., Perez-Alday, E., Vargas-Luna, M., \& Riu, J. P. (2015). Tidal volume monitoring by electrical impedance tomography (EIT) using different regions of interest (ROI): Calibration equations. Biomedical Signal Processing and Control, 18, 102-109. http://doi.org/10.1016/j.bspc.2014.12.004

Bates, J. H. T. (2009). Lung Mechanics: An Inverse Modeling Approach. Cambridge University Press.

Bates, J. H. T., \& Irvin, C. G. (2002). Time dependence of recruitment and derecruitment in the lung: a theoretical model. Journal of Applied Physiology, 93(2), 705-713. http://doi.org/10.1152/japplphysiol.01274.2001

Ben-Tal, A. (2006). Simplified models for gas exchange in the human lungs. Journal of Theoretical Biology, 238(2), 474-495. http://doi.org/10.1016/j.jtbi.2005.06.005

Bernard, G. R. (2005). Acute respiratory distress syndrome: a historical perspective. American Journal of Respiratory and Critical Care Medicine, 172(7), 798-806. http://doi.org/10.1164/rccm.200504-6630E

Bodenstein, M., David, M., \& Markstaller, K. (2009). Principles of electrical impedance tomography and its clinical application. Critical Care Medicine, 37(2), 713-724. http://doi.org/10.1097/CCM.0b013e3181958d2f

Branson, R. D. (2012). Modes to Facilitate Ventilator Weaning. Respiratory Care, 57(10), 1635-1648. http://doi.org/10.4187/respcare.02081

Branson, R. D., \& Johannigman, J. a. (2009). Innovations in mechanical ventilation. Respiratory Care, 54(7), 933-947. http://doi.org/10.4187/002013209793800277 
Briel, M., Meade, M. O., Mercat, A., Brower, R. G., Talmor, D., Walter, S. D., ... Guyatt, G. H. (2010). Higher vs Lower Positive End-Expiratory Pressure in Patients With Acute Lung Injury. JAMA: The Journal of the American Medical Association, 303(9), 865-873. http://doi.org/10.1001/jama.2010.218

Brochard, L., Mancebo, J., Wysocki, M., Lofaso, F., Conti, G., Rauss, A., ... Harf, A. (1995). Noninvasive Ventilation for Acute Exacerbations of Chronic Obstructive Pulmonary Disease. The New England Journal of Medicine, 333(13), 667-676. http://doi.org/10.1345/aph.1E469

Brochard, L., Rauss, A., Benito, S., Conti, G., Mancebo, J., Rekik, N., ... Lemaire, F. (1994). Comparison of three methods of gradual withdrawal from ventilatory support during weaning from mechanical ventilation. American Journal of Respiratory and Critical Care Medicine, 150(4), 896903. http://doi.org/10.1164/ajrccm.150.4.7921460

Brower, R. G., Lanken, P. N., Macintyre, N., Matthay, M. A., Morris, A., Ancukiewicz, M., ... The National Heart Lung and Blood Institute ARDS Clinical Trials. (2004). Higher versus Lower Positive EndExpiratory Pressures in Patients with the Acute Respiratory Distress Syndrome. The New England Journal of Medicine, 351(4), 113-116. http://doi.org/10.1056/NEJMp1415160

Brower, R. G., Matthay, M. A., Morris, A., Schoenfeld, D. A., Thompson, B. T., Wheeler, A., \& The Acute Respiratory Distress Syndrome Network. (2000). Ventilation With Lower Tidal Volumes As Compared With Traditional Tidal Volumes for Acute Lung Injury and the Acute Respiratory Distress Syndrome. The New England Journal of Medicine, 342(18), 1301-1308. http://doi.org/10.1056/NEJM200005043421801

Burrowes, K. S., Clark, A. R., Marcinkowski, A., Wilsher, M. L., Milne, D. G., \& Tawhai, M. H. (2011). Pulmonary embolism: predicting disease severity. Philosophical Transactions of the Royal Society A: Mathematical, Physical and Engineering Sciences, 369(1954), 4255-4277. http://doi.org/10.1098/rsta.2011.0129

Burrowes, K. S., Clark, A. R., \& Tawhai, M. H. (2011). Blood flow redistribution and ventilationperfusion mismatch during embolic pulmonary arterial occlusion. Pulmonary Circulation, 1(3), 365-76. http://doi.org/10.4103/2045-8932.87302

Burrowes, K. S., De Backer, J., Smallwood, R., Sterk, P. J., Gut, I., Wirix-Speetjens, R., ... Brightling, C. (2013). Multi-scale computational models of the airways to unravel the pathophysiological mechanisms in asthma and chronic obstructive pulmonary disease (AirPROM). Interface Focus, 3(2). http://doi.org/10.1098/rsfs.2012.0057

Burrowes, K. S., Swan, A. J., Warren, N. J., \& Tawhai, M. H. (2008). Towards a virtual lung: Multi-scale, multi-physics modelling of the pulmonary system. Philosophical Transactions of the Royal Society A: Mathematical, Physical and Engineering Sciences, 366(1879), 3247-3263. http://doi.org/10.1098/rsta.2008.0073

Burrowes, K. S., \& Tawhai, M. H. (2006). Computational predictions of pulmonary blood flow gradients: Gravity versus structure. Respiratory Physiology and Neurobiology, 154(3), 515-523. http://doi.org/10.1016/j.resp.2005.11.007

Carvalho, A. R. S., Jandre, F. C., Pino, A. V, Bozza, F. a, Salluh, J., Rodrigues, R., ... Giannella-Neto, A. (2007). Positive end-expiratory pressure at minimal respiratory elastance represents the best compromise between mechanical stress and lung aeration in oleic acid induced lung injury. Critical Care, 11(4), R86. http://doi.org/10.1186/cc6093

Cavalcanti, A. B., Suzumura, É. A., Laranjeira, L. N., Paisani, D. de M., Damiani, L. P., Guimarães, H. P., ... Ribeiro de Carvalho, C. R. (2017). Effect of Lung Recruitment and Titrated Positive EndExpiratory Pressure (PEEP) vs Low PEEP on Mortality in Patients With Acute Respiratory Distress Syndrome. JAMA: The Journal of the American Medical Association, 318(14), 1335. http://doi.org/10.1001/jama.2017.14171

Chase, J. G., Desaive, T., \& Preiser, J.-C. (2016). Virtual patients and virtual cohorts: a new way to think about the design and implementation of personalised ICU treatments. In J.-L. Vincent (Ed.), Annual Update in Intensive Care and Emergency Medicine 2016 (Vol. 2, pp. 435-448). Springer.

Chase, J. G., Le Compte, A. J., Preiser, J.-C., Shaw, G. M., Penning, S., \& Desaive, T. (2011). Physiological 
modeling, tight glycemic control, and the ICU clinician: what are models and how can they affect practice? Annals of Intensive Care, 1(1), 11. http://doi.org/10.1186/2110-5820-1-11

Chase, J. G., Moeller, K., Shaw, G. M., Schranz, C., Chiew, Y.-S., \& Desaive, T. (2014). When the value of gold is zero. BMC Research Notes, 7(1), 5-7. http://doi.org/10.1186/1756-0500-7-404

Chase, J. G., Preiser, J.-C., Dickson, J. L., Pironet, A., Chiew, Y.-S., Pretty, C. G., ... Desaive, T. (2018). Next-generation, personalised, model-based critical care medicine: a state-of-the art review of in silico virtual patient models, methods, and cohorts, and how to validation them. BioMedical Engineering OnLine, 17(1), 24.

Chase, J. G., Shaw, G. M., Le Compte, A., Lonergan, T., Willacy, M., Wong, X. W., ... Hann, C. (2008). Implementation and evaluation of the SPRINT protocol for tight glycaemic control in critically ill patients: A clinical practice change. Critical Care, 12(2), 1-15. http://doi.org/10.1186/cc6868

Chase, J. G., Shaw, G. M., Lotz, T., Lecompte, A., Wong, J., Lin, J., ... Hann, C. E. (2007). Model-based insulin and nutrition administration for TGC in critical care. Current Drug Delivery, 4, 283-296.

Chase, J. G., Suhaimi, F., Penning, S., Preiser, J.-C., Le Compte, A. J., Lin, J., ... Desaive, T. (2010). Validation of a model-based virtual trials method for tight glycemic control in intensive care. BioMedical Engineering OnLine, 9(1), 84. http://doi.org/10.1186/1475-925X-9-84

Chatburn, R. L. (2004). Computer control of mechanical ventilation. Respiratory Care, 49(5), 507-17. Retrieved from http://www.ncbi.nlm.nih.gov/pubmed/15107139

Chelucci, G. L., Brunett, F., Ava-santuccit, J. D., Dhainautt, J. F., Paccalyt, D., Armaganidis, A., \& Lockhartt, A. (1991). A single-compartment model cannot describe passive expiration in intubated , paralysed humans. European Respiratory Journal, 4, 458-464.

Chiew, Y.-S., Chase, J. G., Shaw, G. M., Sundaresan, A., \& Desaive, T. (2011). Model-based PEEP Optimisation in Mechanical Ventilation. BioMedical Engineering OnLine, 10(1), 111. http://doi.org/10.1186/1475-925X-10-111

Chiew, Y.-S., Pretty, C. G., Docherty, P. D., Lambermont, B., Shaw, G. M., Desaive, T., \& Chase, J. G. (2015). Time-Varying Respiratory System Elastance: A Physiological Model for Patients Who Are $\begin{array}{lllll}\text { Spontaneously Breathing. PLOS ONE, 10(1), e0114847. } & \text {. }\end{array}$ http://doi.org/10.1371/journal.pone.0114847

Chiew, Y.-S., Pretty, C. G., Shaw, G. M., Chiew, Y. W., Lambermont, B., Desaive, T., \& Chase, J. G. (2015). Feasibility of titrating PEEP to minimum elastance for mechanically ventilated patients. Pilot and Feasibility Studies, 1(1), 1-10. http://doi.org/10.1186/s40814-015-0006-2

Chiew, Y.-S., Tan, C. P., Chase, J. G., Chiew, Y. W., Desaive, T., Ralib, A. M., \& Mat Nor, M. B. (2018). Assessing mechanical ventilation asynchrony through iterative airway pressure reconstruction. Computer Methods and Programs in Biomedicine, 157, 217-224. http://doi.org/10.1016/j.cmpb.2018.02.007

Chis, O. T., Banga, J. R., \& Balsa-Canto, E. (2011). Structural identifiability of systems biology models: A critical comparison of methods. PLOS ONE, 6(11). http://doi.org/10.1371/journal.pone.0027755

Cobelli, C., \& DiStefano, J. J. (1980). Parameter and structural identifiability concepts and ambiguities: a critical review and analysis. American Journal of Physiology-Regulatory, Integrative and Comparative Physiology, 239(1), R7-R24. http://doi.org/10.1152/ajpregu.1980.239.1.R7

Cohen, I. L., \& Booth, F. V. (1994). Cost containment and mechanical ventilation in the United States. New Horizons (Baltimore, Md.), 2(3), 283-90. Retrieved from http://www.ncbi.nlm.nih.gov/pubmed/8087585

Corrado, A., \& Gorini, M. (2002). Negative-pressure ventilation: Is there still a role? European Respiratory Journal, 20(1), 187-197. http://doi.org/10.1183/09031936.02.00302602

Crampin, E. J., Halstead, M., Hunter, P., Nielsen, P., Noble, D., Smith, N., \& Tawhai, M. H. (2004). Computational physiology and the physiome project. Experimental Physiology, 89(1), 1-26. http://doi.org/10.1113/expphysiol.2003.026740

Crotti, S., Mascheroni, D., Caironi, P., Pelosi, P., Ronzoni, G., Mondino, M., ... Gattinoni, L. (2001). Recruitment and Derecruitment during Acute Respiratory Failure. American Journal of 
Respiratory \& Critical Care Medicine, 164, 131-140.

Dasta, J. F., McLaughlin, T. P., Mody, S. H., \& Piech, C. T. (2005). Daily cost of an intensive care unit day The contribution of mechanical ventilation. Critical Care Medicine, 33(6), 1266-1271. http://doi.org/10.1097/01.CCM.0000164543.14619.00

Davidson, S. M., Redmond, D. P., Laing, H., White, R., Radzi, F., Chiew, Y.-S., ... Chase, J. G. (2014). Clinical Utilisation of Respiratory Elastance (CURE): Pilot trials for the optimisation of mechanical ventilation settings for the critically III. IFAC Proceedings Volumes (IFAC-PapersOnline), 19(October), 8403-8408. http://doi.org/10.13140/2.1.1772.2882

de Matos, G. F. J., Stanzani, F., Passos, R. H., Fontana, M. F., Albaladejo, R., Caserta, R. E., ... Barbas, C. S. V. (2012). How large is the lung recruitability in early acute respiratory distress syndrome: A prospective case series of patients monitored by computed tomography. Critical Care, 16(1), 114. http://doi.org/10.1186/cc10602

Deans, K. J., Minneci, P. C., Cui, X., Banks, S. M., Natanson, C., \& Eichacker, P. Q. (2005). Mechanical ventilation in ARDS: One size does not fit all. Critical Care Medicine (Vol. 33). http://doi.org/10.1097/01.CCM.0000162384.71993.A3

Dellamonica, J., Lerolle, N., Sargentini, C., Beduneau, G., Di Marco, F., Mercat, A., ... Brochard, L. (2011). PEEP-induced changes in lung volume in acute respiratory distress syndrome. Two methods to estimate alveolar recruitment. Intensive Care Medicine, 37(10), 1595-1604. http://doi.org/10.1007/s00134-011-2333-y

Dickson, J. L., Gunn, C. A., \& Chase, J. G. (2014). Humans are Horribly Variable. International Journal of Clinical and Medical Imaging, 1(2), 1000142.

Dickson, J. L., Stewart, K. W., Pretty, C. G., Flechet, M., Desaive, T., Penning, S., ... Chase, J. G. (2018). Generalisability of a Virtual Trials Method for Glycaemic Control in Intensive Care. IEEE Transactions on Biomedical Engineering, 65(7), 1543-1553. http://doi.org/10.1109/TBME.2017.2686432

Dirocco, J. D., Pavone, L. A., Carney, D. E., Lutz, C. J., Gatto, L. A., Landas, S. K., \& Nieman, G. F. (2006). Dynamic alveolar mechanics in four models of lung injury. Intensive Care Medicine, 32, 140-148. http://doi.org/10.1007/s00134-005-2854-3

Docherty, P. D., Chase, J. G., Lotz, T. F., \& Desaive, T. (2011). A graphical method for practical and informative identifiability analyses of physiological models: a case study of insulin kinetics and sensitivity. BioMedical Engineering OnLine, 10(1), 39. http://doi.org/10.1186/1475-925X-10-39

Docherty, P. D., Schranz, C., Chiew, Y.-S., Möller, K., \& Chase, J. G. (2014). Reformulation of the pressure-dependent recruitment model (PRM) of respiratory mechanics. Biomedical Signal Processing and Control, 12, 47-53. http://doi.org/10.1016/j.bspc.2013.12.001

Donahoe, M. (2011). Acute respiratory distress syndrome: A clinical review. Pulmonary Circulation, 1(2), 192-211. http://doi.org/10.4103/2045-8932.83454

Dreyfuss, D., \& Saumon, G. (1998). Ventilator-induced lung injury: Lessons from experimental studies. American Journal of Respiratory and Critical Care Medicine, 157(1), 294-323. http://doi.org/10.1164/ajrccm.157.1.9604014

Dyhr, T., Laursen, N., \& Larsson, A. (2002). Effects of lung recruitment maneuver and positive endexpiratory pressure on lung volume, respiratory mechanics and alveolar gas mixing in patients ventilated after cardiac surgery. Acta Anaesthesiologica Scandinavica, 46(6), 717-725. http://doi.org/10.1034/j.1399-6576.2002.460615.x

Eom, J., Xu, X. G., De, S., \& Shi, C. (2010). Predictive modeling of lung motion over the entire respiratory cycle using measured pressure-volume data, 4DCT images, and finite-element analysis. Medical Physics, 37(8), 4389-4400. http://doi.org/10.1118/1.3455276

Evans, A., Shaw, G. M., Le Compte, A., Tan, C.-S., Ward, L., Steel, J., ... Chase, J. G. (2011). Pilot proof of concept clinical trials of Stochastic Targeted (STAR) glycemic control. Annals of Intensive Care, 1(1), 38. http://doi.org/10.1186/2110-5820-1-38

Flores, M., Glusman, G., Brogaard, K., Price, N., \& Hood, L. (2013). P4 medicine: how systems medicine will transform the healthcare sector and society. Personalized Medicine, 10(6), 565-576. 
http://doi.org/10.15252/embr.201439609

Frerichs, I., Schiffmann, H., Oehler, R., Dudykevych, T., Hahn, G., Hinz, J., \& Hellige, G. (2003). Distribution of lung ventilation in spontaneously breathing neonates lying in different body positions. Intensive Care Medicine, 29(5), 787-794. http://doi.org/10.1007/s00134-003-1726-y

Futier, E., Constantin, J.-M., Paugam-Burtz, C., Pascal, J., Eurin, M., Neuschwander, A., ... Jaber, S. (2013). A Trial of Intraoperative Low-Tidal-Volume Ventilation in Abdominal Surgery. New England Journal of Medicine, 369(5), 428-437. http://doi.org/10.1056/NEJMoa1301082

Garcia, C. S. N. B., Prota, L. F. M., Morales, M. M., Romero, P. V., Zin, W. a., \& Rocco, P. R. M. (2006). Understanding the mechanisms of lung mechanical stress. Brazilian Journal of Medical and Biological Research, 39(6), 697-706. http://doi.org/10.1590/S0100-879X2006000600001

Gattinoni, L., Carlesso, E., Brazzi, L., \& Caironi, P. (2010). Positive end-expiratory pressure. Current Opinion in Critical Care, 16(1), 39-44. http://doi.org/10.1097/MCC.0b013e3283354723

Girard, T. D., \& Bernard, G. R. (2007). Mechanical ventilation in ARDS: A state-of-the-art review. Chest, 131(3), 921-929. http://doi.org/10.1378/chest.06-1515

Gong, B., Krueger-Ziolek, S., Moeller, K., Schullcke, B., \& Zhao, Z. (2015). Electrical impedance tomography: Functional lung imaging on its way to clinical practice? Expert Review of Respiratory Medicine, 9(6), 721-737. http://doi.org/10.1586/17476348.2015.1103650

Guttmann, J., Eberhard, L., Fabry, B., Bertschmann, W., \& Wolff, G. (1993). Continuous calculation of intratracheal pressure in tracheally intubated patients. Anesthesiology. http://doi.org/10.1097/00000542-199309000-00014

Guttmann, J., Eberhard, L., Fabry, B., Bertschmann, W., Zeravik, J., Adolph, M., ... Wolff, G. (1995). Time constant/volume relationship of passive expiration in mechanically ventilated ARDS patients. European Respiratory Journal, 8(1), 114-120. http://doi.org/10.1183/09031936.95.08010114

Guttmann, J., Kessler, V., Mols, G., Hentschel, R., Haberthür, C., \& Geiger, K. (2000). Continuous calculation of intratracheal pressure in the presence of pediatric endotracheal tubes. Critical Care Medicine, 28(4), 1018-1026. http://doi.org/10.1097/00003246-200004000-00018

Hager, D. N., Krishnan, J. a., Hayden, D. L., \& Brower, R. G. (2005). Tidal volume reduction in patients with acute lung injury when plateau pressures are not high. American Journal of Respiratory and Critical Care Medicine, 172(10), 1241-1245. http://doi.org/10.1164/rccm.200501-048CP

Hahn, G., Frerichs, I., Kleyer, M., \& Heilige, G. (1996). Local mechanics of the lung tissue determined by functional EIT. Physiological Measurement, 17(4 SUPPL. A). http://doi.org/10.1088/0967$3334 / 17 / 4 \mathrm{~A} / 020$

Heizmann, S., Baumgärtner, M., Zhao, Z., \& Möller, K. (2014). 3-D Lung Visualization Using Electrical Impedance Tomography Combined with Body Plethysmography. In The 15th International Conference on Biomedical Engineering (Vol. 43, pp. 172-173). http://doi.org/10.1007/978-3319-02913-9

Herridge, M. S., Cheung, A. M., Tansey, C. M., Matte-Martyn, A., Diaz-Granados, N., Al-Saidi, F., ... Slutsky, A. S. (2003). One-Year Outcomes in Survivors of the Acute Respiratory Distress Syndrome. The New England Journal of Medicine, 348(8), 683-693. http://doi.org/10.1136/jech.2009.090662

Hess, D. R. (2015). Recruitment Maneuvers and PEEP Titration. Respiratory Care, 60(11), 1688-1704.

Hetland, B., Lindquist, R., \& Chlan, L. L. (2015). The influence of music during mechanical ventilation and weaning from mechanical ventilation: A review. Heart \& Lung: The Journal of Acute and Critical Care, 44(5), 416-425. http://doi.org/10.1016/j.hrtlng.2015.06.010

Hodgson, C. L., Tuxen, D. V, Davies, A. R., Bailey, M. J., Higgins, A. M., Holland, A. E., ... Nichol, A. D. (2011). A randomised controlled trial of an open lung strategy with staircase recruitment, titrated PEEP and targeted low airway pressures in patients with acute respiratory distress syndrome. Critical Care, 15(3), R133. http://doi.org/10.1186/cc10249

Iglesias, M., Martinez, E., Badia, J. R., Macchiarini, P., Iglesias, M., Martinez, E., \& Badia, J. R. (2008). Severe Acute Respiratory Distress Syndrome. In Advances in Extra-Corporeal Perfusion Therapies 
(pp. 237-244). http://doi.org/10.1016/j.athoracsur.2007.06.004

Jandre, F. C., Modesto, F. C., Carvalho, A. R. S., \& Giannella-Neto, A. (2008). The endotracheal tube biases the estimates of pulmonary recruitment and overdistension. Medical and Biological Engineering and Computing, 46(1), 69-73. http://doi.org/10.1007/s11517-007-0227-5

Jandre, F. C., Pino, A., Lacorte, I., Neves, J. H. S., \& Giannella-Neto, A. (2004). A Closed-Loop Mechanical Ventilation Controller With Explicit Objective Functions. Teee Transactions on Biomedical Engineering, 51(N. 5), 823-831.

Jobe, A. H. (2009). Lung Recruitment for Ventilation: Does It Work, and is It Safe? Journal of Pediatrics, 154(5), 635-636. http://doi.org/10.1016/j.jpeds.2009.01.059

Kacmarek, R. M., Villar, J., Sulemanji, D., Montiel, R., Ferrando, C., Blanco, J., ... Suarez-Sipmann, F. (2016). Open lung approach for the acute respiratory distress syndrome: A pilot, randomized controlled trial. Critical Care Medicine, 44(1), 32-42. http://doi.org/10.1097/CCM.0000000000001383

Kannangara, D. O., Newberry, F., Howe, S., Major, V., Redmond, D., Szlavecs, A., ... Chase, J. G. (2016). Estimating the true respiratory mechanics during asynchronous pressure controlled ventilation. Biomedical Signal Processing and Control, 30, 70-78. http://doi.org/10.1016/j.bspc.2016.06.014

Kárason, S., Antonsen, K., Åneman, A., Möller, A., Åvall, A., Samuelsson, A., ... Aneman, A. (2002). Ventilator treatment in the Nordic countries. A multicenter survey. Acta Anaesthesiologica Scandinavica, 46(9), 1053-61. http://doi.org/10.1034/j.1399-6576.2002.460901.x

Karason, S., Sondergaard, S., Lundin, S., Wiklund, J., \& Stenqvist, O. (2001). Direct tracheal airway pressure measurements are essential for safe and accurate dynamic monitoring of respiratory mechanics. A laboratory study. Acta Anaesthesiologica Scandinavica, 45, 1046-1050. http://doi.org/10.1034/j.1399-6576.2001.450207.x

Karsten, J., Bohlmann, M. K., Sedemund-Adib, B., Wnent, J., Paarmann, H., Iblher, P., ... Heinze, H. (2013). Electrical impedance tomography may optimize ventilation in a postpartum woman with respiratory failure. International Journal of Obstetric Anesthesia, 22(1), 67-71. http://doi.org/10.1016/j.ijoa.2012.09.002

Kenneth Jamerson, M.D., Michael A. Weber, M.D., George L. Bakris, M.D., Björn Dahlöf, M.D., Bertram Pitt, M.D., Victor Shi, M.D., Allen Hester, Ph.D., Jitendra Gupte, M.S., Marjorie Gatlin, M.D., and Eric J. Velazquez, M.D., for the A. trial investigators*, \& Abstract. (2017). Functional Disability 5 Years after Acute Respiratory Distress Syndrome Margaret, 1315-1323. http://doi.org/10.1056/NEJMoa1706198

Kunst, P. W. A., Noordegraaf, A. V., Straver, B., Serrano, R. E., De Lema, B., Casas, O., \& Frerichs, I. (2000). Electrical impedance tomography (EIT) in applications related to lung and ventilation: a review of experimental and clinical activities. Physiol. Meas, 21. Retrieved from http://iopscience.iop.org/0967-3334/21/2/201

Lambermont, B., Ghuysen, A., Janssen, N., Morimont, P., Hartstein, G., Gerard, P., \& D’Orio, V. (2008). Comparison of functional residual capacity and static compliance of the respiratory system during a positive end-expiratory pressure (PEEP) ramp procedure in an experimental model of acute respiratory distress syndrome. Critical Care, 12(4), R91. http://doi.org/10.1186/cc6961

Langdon, R., Docherty, P. D., Chiew, Y.-S., \& Chase, J. G. (2016). Extrapolation of a non-linear autoregressive model of pulmonary mechanics. Mathematical Biosciences, 284, 32-39. http://doi.org/10.1016/j.mbs.2016.08.001

Langdon, R., Docherty, P. D., Chiew, Y.-S., Damanhuri, N. S., \& Chase, J. G. (2015). Implementation of a non-linear autoregressive model with modified Gauss-Newton parameter identification to determine pulmonary mechanics of respiratory patients that are intermittently resisting ventilator flow patterns. IFAC-PapersOnLine, 28(20), 354-359. http://doi.org/10.1016/j.ifacol.2015.10.165

Langdon, R., Docherty, P. D., Chiew, Y.-S., Möller, K., \& Chase, J. G. (2016). Use of basis functions within a non-linear autoregressive model of pulmonary mechanics. Biomedical Signal Processing and Control, 27, 44-50. http://doi.org/10.1016/j.bspc.2016.01.010 
Langdon, R., Docherty, P. D., Mansell, E. J., \& Chase, J. G. (2018). Accurate and precise prediction of insulin sensitivity variance in critically ill patients. Biomedical Signal Processing and Control, 39, 327-335. http://doi.org/10.1016/j.bspc.2017.08.010

Laubscher, T. P., Frutiger, A., Fanconi, S., \& Brunner, J. X. (1996). The automatic selection of ventilation parameters during the initial phase of mechanical ventilation. Intensive Care Medicine, 22(3), 199-207. http://doi.org/10.1007/BF01712237

Laubscher, T. P., Frutiger, A., Fanconi, S., Jutzi, H., \& Brunner, J. X. (1994). Automatic selection of tidal volume, respiratory frequency and minute ventilation in intubated ICU patients as startup procedure for closed-loop controlled ventilation. International Journal of Clinical Monitoring and Computing, 11(1), 19-30. http://doi.org/10.1007/BF01132840

Laufer, B., Docherty, P. D., Knörzer, A., Chiew, Y.-S., Langdon, R., Möller, K., \& Chase, J. G. (2017). Performance of variations of the dynamic elastance model in lung mechanics. Control Engineering Practice, 58, 262-267. http://doi.org/10.1016/j.conengprac.2016.03.004

Lellouche, F., Mancebo, J., Jolliet, P., Roeseler, J., Schortgen, F., Dojat, M., ... Brochard, L. (2006). A multicenter randomized trial of computer-driven protocolized weaning from mechanical ventilation. American Journal of Respiratory and Critical Care Medicine, 174(8), 894-900. http://doi.org/10.1164/rccm.200511-17800C

Lin, J., Lee, D., Chase, J. G., Shaw, G. M., Compte, A. Le, Lotz, T., ... Hann, C. E. (2007). Stochastic Modelling of Insulin Sensitivity and Adaptive Glycemic Control for Critical Care. Computer Methods and Programs in Biomedicine, 89(2), 141-152.

Ljung, L. (1999). System identification : theory for the user (2nd Editio). Upper Saddle River, NJ: Prentice Hall.

Lorx, A., Suki, B., Hercsuth, M., Szabó, B., Pénzes, I., Boda, K., \& Hantos, Z. (2010). Airway and tissue mechanics in ventilated patients with pneumonia. Respiratory Physiology and Neurobiology, 171(2), 101-109. http://doi.org/10.1016/j.resp.2010.03.004

Lucangelo, U., Bernabè, F., \& Blanch, L. (2007). Lung mechanics at the bedside: make it simple. Current Opinion in Critical Care, 13(1), 64-72. http://doi.org/10.1097/MCC.0b013e32801162df

Ma, B., \& Bates, J. H. T. (2010). Modeling the complex dynamics of derecruitment in the lung. Annals of Biomedical Engineering, 38(11), 3466-3477. http://doi.org/10.1007/s10439-010-0095-2

Maca, J., Jor, O., Holub, M., Sklienka, P., Bur a, F., Burda, M., ... ev ik, P. (2017). Past and Present ARDS Mortality Rates: A Systematic Review. Respiratory Care, 62(1), 113-122. http://doi.org/10.4187/respcare.04716

Major, V. J., Shaw, G. M., \& Chase, J. G. (2018). Biomedical Engineer's Guide to the Clinical Aspects of Intensive Care Mechanical Ventilation. BioMedical Engineering OnLine. http://doi.org/10.1186/s12938-018-0599-9

Marelich, G. P. (2000). Protocol Weaning of Mechanical Ventilation in Medical and Surgical Patients by RespiratoryCare Practitioners and Nurses *. Chest, 118(2), 459. http://doi.org/10.1378/chest.118.2.459

Marini, J. J. (1994). Ventilation of the acute respiratory distress syndrome: looking for Mr. Goodmode. Anesthesiology, 80(5), 972-975.

Massa, C. B., Allen, G. B., \& Bates, J. H. T. (2008). Modeling the dynamics of recruitment and derecruitment in mice with acute lung injury. Journal of Applied Physiology, 105(6), 1813-1821. http://doi.org/10.1152/japplphysiol.90806.2008

Mead, J., \& Whittenberger, J. L. (1953). Physical Properties of Human Lungs Measured During Spontaneous Respiration. Journal of Applied Physiology, 5(12), 779-796. Retrieved from http://jap.physiology.org/content/5/12/779.short

Meade, M., Guyatt, G. H., Cook, D. J., Griffith, L. E., Sinuff, T., Kergl, C., ... Epstein, S. K. (2001). Predicting Success in Weaning From Mechanical Ventilation. CHEST Journal, 120(6_suppl), $400 \mathrm{~S}$. http://doi.org/10.1378/chest.120.6_suppl.400S

Meade, M. O., Cook, D. J., Arabi, Y. M., Cooper, D. J., Davies, A. R., Hand, L. E., ... Stewart, T. E. (2008). Ventilation Strategy Using Low Tidal Volumes, Recruitment Maneuvers, and High Positive End- 
Expiratory Pressure for Acute Lung Injury and Acute Respiratory Distress Syndrome. JAMA: The Journal of the American Medical Association, 299(6), 637-645. http://doi.org/10.1001/jama.299.6.637

Meade, M. O., Cook, D. J., Griffith, L. E., Rrt, L. E. H., Lapinsky, S. E., Stewart, T. E., ... Guyatt, G. H. (2008). A Study of the Physiologic Responses to a Lung Recruitment Maneuver in Acute Lung Injury and Acute Respiratory Distress Syndrome. Respiratory Care, 53(11), 1441-1449.

Mercat, A., Richard, J.-C. M., Vielle, B., Jaber, S., Osman, D., Diehl, J.-L., ... Expiratory Pressure (Express) Study Group, for the. (2008). Positive End-Expiratory Pressure Setting in Adults With Acute Lung Injury and Acute Respiratory Distress Syndrome. JAMA: The Journal of the American Medical Association, 299(6), 646. http://doi.org/10.1001/jama.299.6.646

Metnitz, P. G. H., Metnitz, B., Moreno, R. P., Bauer, P., Sorbo, L. Del, Hoermann, C., ... Ranieri, V. M. (2009). Epidemiology of Mechanical Ventilation: Analysis of the SAPS 3 Database. Intensive Care Medicine, 35(5), 816-824. http://doi.org/10.1007/s00134-009-1449-9

Mezidi, M., Parrilla, F. J., Yonis, H., Riad, Z., Böhm, S. H., Waldmann, A. D., ... Guérin, C. (2018). Effects of positive end-expiratory pressure strategy in supine and prone position on lung and chest wall mechanics in acute respiratory distress syndrome. Annals of Intensive Care, 8(1). http://doi.org/10.1186/s13613-018-0434-2

Mols, G., Priebe, H. J., \& Guttmann, J. (2006). Alveolar recruitment in acute lung injury. British Journal of Anaesthesia, 96(2), 156-166. http://doi.org/10.1093/bja/aei299

Mombaerts, L., Thomas, F., Signal, M., Desaive, T., \& Chase, J. G. (2015). Continuous glucose monitoring: Using CGM to guide insulin therapy virtual trials results. IFAC-PapersOnLine, 28(20), 112-117. http://doi.org/10.1016/j.ifacol.2015.10.124

Morton, S. E., Chiew, Y.-S., Pretty, C. G., Moltchanova, E., Scarrott, C., Redmond, D. P., ... Chase, J. G. (2017). Effective sample size estimation for a mechanical ventilation trial through Monte-Carlo simulation: Length of mechanical ventilation and Ventilator Free Days. Mathematical Biosciences, 284, 21-31. http://doi.org/10.1016/j.mbs.2016.06.001

Morton, S. E., Dickson, J. L., Chase, J. G., Docherty, P. D., Desaive, T., Howe, S. L., ... Tawhai, M. H. (2018). A virtual patient model for mechanical ventilation. Computer Methods and Programs in Biomedicine, 165, 77-87. http://doi.org/https://doi.org/10.1016/j.cmpb.2018.08.004

Morton, S. E., Dickson, J. L., Chase, J. G., Docherty, P. D., Howe, S. L., Shaw, G. M., \& Tawhai, M. H. (2018a). Basis function identification of lung mechanics in mechanical ventilation for predicting outcomes of therapy changes: A first virtual patient. IFAC-PapersOnLine, 51(15), 299-304. http://doi.org/10.1016/j.ifacol.2018.09.151

Morton, S. E., Dickson, J. L., Chase, J. G., Docherty, P. D., Howe, S. L., Shaw, G. M., \& Tawhai, M. H. (2018b). Development of a Predictive Pulmonary Elastance Model to Describe Lung Mechanics throughout Recruitment Manoeuvres. IFAC-PapersOnLine, 51(27), 215-220. http://doi.org/10.1016/j.ifacol.2018.11.640

Morton, S. E., Docherty, P. D., Dickson, J. L., \& Chase, J. G. (2018). An analysis of the impact of the inclusion of expiration data on the fitting of a predictive pulmonary elastance model. Current Directions in Biomedical Engineering, 4(1), 255-258.

Morton, S. E., Knopp, J. L., Docherty, P. D., Shaw, G. M., \& Chase, J. G. (2018). Validation of a Modelbased Method for Estimating Functional Volume Gains during Recruitment Manoeuvres in Mechanical Ventilation. IFAC-PapersOnLine, 51(27), 231-236. http://doi.org/10.1016/j.ifacol.2018.11.637

Nieman, G. F., Satalin, J., Andrews, P., Wilcox, K., Aiash, H., Baker, S., ... Habashi, N. M. (2018). Preemptive mechanical ventilation based on dynamic physiology in the alveolar microenvironment. Journal of Trauma and Acute Care Surgery, 85(6), 1081-1091. http://doi.org/10.1097/TA.0000000000002050

Nieman, G. F., Satalin, J., Kollisch-Singule, M., Andrews, P., Aiash, H., Habashi, N. M., \& Gatto, L. A. (2017). Physiology in Medicine: Understanding dynamic alveolar physiology to minimize ventilator-induced lung injury. Journal of Applied Physiology, 122(6), 1516-1522. 
http://doi.org/10.1152/japplphysiol.00123.2017

Pelosi, P., Goldner, M., Mckibben, A., Adams, A. B., Eccher, G., Caironi, P., ... Marini, J. J. (2001). Recruitment and Derecruitment During Acute Respiratory Failure. American Journal of Respiratory and Critical Care Medicine, 164, 122-130.

Penning, S., Lambermont, B., Desaive, T., Pretty, C., \& Chase, J. G. (2014). In silico assessment of a computerized model-based glycaemic control approach in a Belgian medical intensive care unit. IFAC Proceedings Volumes (IFAC-PapersOnline), 19, 9913-9918. http://doi.org/10.3182/20140824-6-ZA-1003.00581

Penning, S., Le Compte, A. J., Moorhead, K. T., Desaive, T., Massion, P., Preiser, J. C., ... Chase, J. G. (2012). First pilot trial of the STAR-Liege protocol for tight glycemic control in critically ill patients. Computer Methods and Programs in Biomedicine, 108(2), 844-859. http://doi.org/10.1016/j.cmpb.2011.07.003

Petrucci, N., \& De Feo, C. (2013). Lung protective ventilation strategy for the acute respiratory distress syndrome. Cochrane Database of Systematic Reviews, 2(4), CD003844. http://doi.org/10.1002/14651858.CD003844.pub4

Pinhu, L., Whitehead, T., Evans, T. W., \& Griffiths, M. (2003). Ventilator-associated lung injury. The Lancet, 6736(January 2014). http://doi.org/10.1016/S0140-6736(03)12329-X

Pintado, M.-C., de Pablo, R., Trascasa, M., Milicua, J.-M., Rogero, S., Daguerre, M., ... Sánchez-García, M. (2013). Individualized PEEP setting in subjects with ARDS: a randomized controlled pilot study. Respiratory Care, 58(9), 1416-23. http://doi.org/10.4187/respcare.02068

Ranieri, V. M., Suter, P. M., Tullio, R. De, Dayer, J. M., Brienza, A., Bruno, F., \& Slutsky, A. S. (2011). Effect of Mechanical Ventilation on Inflammatory Mediators in Patients with Acute Respiratory Distress Syndrome. Journal of the American Medical Association, 281(1), 54-61.

Riedel, T., Richards, T., \& Schibler, A. (2005). The value of electrical impedance tomography in assessing the effect of body position and positive airway pressures on regional lung ventilation in spontaneously breathing subjects. Intensive Care Medicine, 31(11), 1522-1528. http://doi.org/10.1007/s00134-005-2734-x

Riedlinger, A., Kretschmer, J., \& Möller, K. (2015). On the practical identifiability of a two - parameter model of pulmonary gas exchange. BioMedical Engineering OnLine, 1-15. http://doi.org/10.1186/s12938-015-0077-6

Rohrer, F. (1925). Physiologie der Atembewegung. In Handbuch der normalen und pathologischen Physiologie: Vol 2 (pp. 70-127). Berlin: Springer-Verlag.

Safaei, S., Blanco, P. J., Müller, L. O., Hellevik, L. R., \& Hunter, P. J. (2018). Bond graph model of cerebral circulation: Toward clinically feasible systemic blood flow simulations. Frontiers in Physiology, 9(MAR), 1-15. http://doi.org/10.3389/fphys.2018.00148

Schoenfeld, D. A., \& Bernard, G. R. (2002). Statistical evaluation of ventilator-free days as an efficacy measure in clinical trials of treatments for acute respiratory distress syndrome, 30(8).

Schranz, C., Docherty, P. D., Chiew, Y.-S., Chase, J. G., \& Möller, K. (2012). Structural identifiability and practical applicability of an alveolar recruitment model for ARDS patients. IEEE Transactions on Biomedical Engineering, 59(12), 3396-3404. http://doi.org/10.1109/TBME.2012.2216526

Simonis, F. D., Binnekade, J. M., Braber, A., Gelissen, H. P., Heidt, J., Horn, J., ... Schultz, M. J. (2015). PReVENT - protective ventilation in patients without ARDS at start of ventilation: study protocol for a randomized controlled trial. Trials, 16(1), 226. http://doi.org/10.1186/s13063-015-0759-1

Sittig, D. F., Pace, N. L., Gardner, R. M., Beck, E., \& Morris, A. H. (1989). Implementation of a Computerized Patient Advice System using the HELP clinical information system. Computers and Biomedical Research, 22(5), 474-487. http://doi.org/10.1016/0010-4809(89)90040-2

Slutsky, A. S. (1993). ACCP Consensus Conference - Mechanical Ventilation. Chest, 104(6), 1833-1859. http://doi.org/10.1378/chest.110.3.866-a

Slutsky, A. S., \& Ranieri, V. M. (2000). Mechanical ventilation: lessons from the ARDSNet trial. Respiratory Research, 1(2), 73-77. http://doi.org/10.1186/rr15

Slutsky, A. S., \& Ranieri, V. M. (2014). Ventilator-Induced Lung Injury. The New England Journal of 
Medicine, 370, 980. http://doi.org/http://dx.doi.org/10.1108/17506200710779521

Slutsky, A. S., \& Tremblay, L. N. (1998). Multiple System Organ Failure: Is Mechanical Ventilation a Contributing Factor? American Journal of Physiology, 157(16), 1721-1725.

Smalley, E. (2018). Clinical trials go virtual, big pharma dives in. Nature Biotechnology, 36(7), 561-562. http://doi.org/10.1038/nbt0718-561

Sobradillo, P., Pozo, F., \& Agustí, Á. (2011). P4 Medicine: The Future Around the Corner. Archivos de Bronconeumologia, 47(1), 35-40. http://doi.org/10.1016/S1579-2129(11)70006-4

Spaeth, J., Daume, K., Goebel, U., Wirth, S., \& Schumann, S. (2016). Increasing positive end-expiratory pressure (re-)improves intraoperative respiratory mechanics and lung ventilation after prone positioning. British Journal of Anaesthesia, 116(6), 838-846. http://doi.org/10.1093/bja/aew115

Spieth, P. M., \& Gama de Abreu, M. (2012). Lung recruitment in ARDS: We are still confused, but on a higher PEEP level. Critical Care, 16(1), 9-10. http://doi.org/10.1186/cc11177

Stahl, C. A., Moeller, K., Schumann, S., Kuhlen, R., Sydow, M., Putensen, C., \& Guttmann, J. (2006). Dynamic versus static respiratory mechanics in acute lung injury and acute respiratory distress syndrome. Critical Care Medicine, 34(8), 2090-2098. http://doi.org/10.1097/01.CCM.0000227220.67613.0D

Stewart, K. W., Pretty, C. G., Tomlinson, H., Thomas, F. L., Homlok, J., Noémi, S. N., ... Chase, J. G. (2016). Safety, efficacy and clinical generalization of the STAR protocol: a retrospective analysis. Annals of Intensive Care, 6(1). http://doi.org/10.1186/s13613-016-0125-9

Suarez-Sipmann, F., Böhm, S. H., Tusman, G., Pesch, T., Thamm, O., Reissmann, H., ... Hedenstierna, G. (2007). Use of dynamic compliance for open lung positive end-expiratory pressure titration in an experimental study. Critical Care Medicine, 35(1), 214-221. http://doi.org/10.1097/01.CCM.0000251131.40301.E2

Sundaresan, A., \& Chase, J. G. (2012). Positive end expiratory pressure in patients with acute respiratory distress syndrome - The past, present and future. Biomedical Signal Processing and Control, 7(2), 93-103. http://doi.org/10.1016/j.bspc.2011.03.001

Sundaresan, A., Yuta, T., Hann, C. E., Chase, J. G., Shaw, G. M., \& Geoffrey Chase, J. (2009). A minimal model of lung mechanics and model-based markers for optimizing ventilator treatment in ARDS patients. Computer Methods and Programs in Biomedicine, 95(2), 166-180. http://doi.org/10.1016/j.cmpb.2009.02.008

Swan, A. J., Clark, A. R., \& Tawhai, M. H. (2012). A computational model of the topographic distribution of ventilation in healthy human lungs. Journal of Theoretical Biology, 300, 222-231. http://doi.org/10.1016/j.jtbi.2012.01.042

Szlavecz, A., Chiew, Y.-S., Redmond, D. P., Beatson, A., Glassenbury, D., Corbett, S., ... Chase, J. G. (2014). The Clinical Utilisation of Respiratory Elastance Software (CURE Soft): a bedside software for real-time respiratory mechanics monitoring and mechanical ventilation management. BioMedical Engineering OnLine, 13(1), 140. http://doi.org/10.1186/1475-925X-13-140

Tawhai, M. H., \& Bates, J. H. T. (2011). Multi-scale lung modeling. Journal of Applied Physiology, 110(5), 1466-1472. http://doi.org/10.1152/japplphysiol.01289.2010

Tawhai, M. H., \& Burrowes, K. S. (2003). Developing integrative computational models of pulmonary structure. Anatomical Record. Part B, New Anatomist, 275(1), 207-218. http://doi.org/10.1002/ar.b.10034

Tawhai, M. H., \& Burrowes, K. S. (2008). Multi-scale Models of the Lung Airways and Vascular System. Integration in Respiratory Control, 605(5), 190-194.

Tawhai, M. H., Hoffman, E. A., \& Lin, C.-L. (2009). The lung physiome: merging imaging-based measures with predictive computational models. Wiley Interdisciplinary Reviews: Systems Biology and Medicine 2009, 1(1), 61-62.

Tawhai, M. H., Pullan, A. J., \& Hunter, P. J. (2000). Generation of an Anatomically Based ThreeDimensional Model of the Conducting Airways. Annals of Biomedical Engineering, 28(7), 793802. http://doi.org/10.1114/1.1289457

Tehrani, F. T. (2008a). Automatic control of mechanical ventilation. Part 1: Theory and history of the 
technology. Journal of Clinical Monitoring and Computing, 22(6), 409-415. http://doi.org/10.1007/s10877-008-9150-z

Tehrani, F. T. (2008b). Automatic control of mechanical ventilation. Part 2: The existing techniques and future trends. Journal of Clinical Monitoring and Computing, 22(6), 417-424. http://doi.org/10.1007/s10877-008-9151-y

Tehrani, F. T. (2013). A control system for mechanical ventilation of passive and active subjects. Computer Methods and Programs in Biomedicine, 110(3), 511-518. http://doi.org/10.1016/j.cmpb.2013.01.013

Tehrani, F. T., \& Roum, J. H. (2008). Intelligent decision support systems for mechanical ventilation. Artificial Intelligence in Medicine, 44(3), 171-182. http://doi.org/10.1016/j.scienta.2009.07.014

Terragni, P., Rosboch, G. L., Lisi, A., Viale, A. G., \& Ranieri, V. M. (2003). How respiratory system mechanics may help in minimising ventilator-induced lung injury in ARDS patients. European Respiratory Journal, 22(Suppl. 42), 15-21. http://doi.org/10.1183/09031936.03.00420303

Tgavalekos, N. T., Tawhai, M. H., Harris, R. S., Mush, G., Vidal-Melo, M., Venegas, J. G., \& Lutchen, K. R. (2005). Identifying airways responsible for heterogeneous ventilation and mechanical dysfunction in asthma: an image functional modeling approach. Journal of Applied Physiology, 99(6), 2388-2397. http://doi.org/10.1152/japplphysiol.00391.2005

Uyttendaele, V., Dickson, J. L., Morton, S. E., Shaw, G. M., Desaive, T., \& Chase, J. G. (2018). Changes in Identified, Model-based Insulin Sensitivity can be used to Improve Risk and Variability Forecasting in Glycaemic Control. IFAC-PapersOnLine, 51(15), 311-316.

Valentini, R., Aquino-Esperanza, J., Bonelli, I., \& Maskin, P. (2014). Gas exchange and lung mechanics in patients with acute respiratory distress syndrome: comparison of three different strategies of positive end expiratory pressure. Journal of Critical Care, 30(2), 334-340. http://doi.org/10.1016/j.jcrc.2014.11.019.

van Drunen, E. J., Chase, J. G., Chiew, Y.-S., Shaw, G. M., \& Desaive, T. (2013). Analysis of different model-based approaches for estimating dFRC for real-time application. BioMedical Engineering OnLine, 12(1), 9. http://doi.org/10.1186/1475-925X-12-9

van Drunen, E. J., Chiew, Y.-S., Pretty, C. G., Shaw, G. M., Lambermont, B., Janssen, N., ... Desaive, T. (2014). Visualisation of time-varying respiratory system elastance in experimental ARDS animal models. BMC Pulmonary Medicine, 14(1), 1-9. http://doi.org/10.1186/1471-2466-14-33

Wallet, F., Delannoy, B., Haquin, A., Debord, S., Leray, V., Bourdin, G., ... Guerin, C. (2013). Evaluation of Recruited Lung Volume at Inspiratory Plateau Pressure With PEEP Using Bedside Digital Chest X-ray in Patients With Acute Lung Injury/ARDS. Respiratory Care, 58(3), 416-423. http://doi.org/10.4187/respcare.01893

Werner, R., Ehrhardt, J., Schmidt, R., \& Handels, H. (2009). Patient-specific finite element modeling of respiratory lung motion using 4D CT image data. Medical Physics, 36(5), 1500-1511. http://doi.org/10.1118/1.3101820

Wunsch, H., Linde-zwirble, W. T., Angus, D. C., Hartman, M. E., Milbrandt, E. B., \& Kahn, J. M. (2010). The epidemiology of mechanical ventilation use in the United States. Critical Care Medicine, 38(10), 1947-1953. http://doi.org/10.1097/CCM.0b013e3181ef4460

Yang, K. L., \& Tobin, M. J. (1992). A Prospective Study of Indexes Predicting the Outcome of Trials of Weaning from Mechanical Ventilation. Survey of Anesthesiology. http://doi.org/10.1097/00132586-199204000-00032

Zhao, Z., Fischer, R., Frerichs, I., Müller-Lisse, U., \& Möller, K. (2012). Regional ventilation in cystic fibrosis measured by electrical impedance tomography. Journal of Cystic Fibrosis, 11(5), 412418. http://doi.org/10.1016/j.jcf.2012.03.011

Zhao, Z., Guttmann, J., \& Möller, K. (2011). Adaptive SLICE method: an enhanced method to determine nonlinear dynamic respiratory system mechanics. Physiological Measurement, 33(1), 51-64. http://doi.org/10.1088/0967-3334/33/1/51

Zhao, Z., Guttmann, J., \& Möller, K. (2012). Assessment of a volume-dependent dynamic respiratory system compliance in ALI/ARDS by pooling breathing cycles. Physiological Measurement, 33(8), 
N61-N67. http://doi.org/10.1088/0967-3334/33/8/N61

Zhao, Z., Pulletz, S., Frerichs, I., Müller-Lisse, U., \& Möller, K. (2014). The EIT-based global inhomogeneity index is highly correlated with regional lung opening in patients with acute respiratory distress syndrome. BMC Research Notes, 7(1). http://doi.org/10.1186/1756-0500-782

Zhao, Z., Steinmann, D., Frerichs, I., Guttmann, J., \& Möller, K. (2010). PEEP titration guided by ventilation homogeneity: a feasibility study using electrical impedance tomography. Critical Care, 14, 1-8.

Zhao, Z., Yun, P. J., Kuo, Y. L., Fu, F., Dai, M., Frerichs, I., \& Möller, K. (2018). Comparison of different functional EIT approaches to quantify tidal ventilation distribution. Physiological Measurement, 39(1), 0-8. http://doi.org/10.1088/1361-6579/aa9eb4

Zhou, T., Dickson, J. L., Shaw, G. M., \& Chase, J. G. (2018). Continuous Glucose Monitoring Measures Can Be Used for Glycemic Control in the ICU: An In-Silico Study. Journal of Diabetes Science and Technology, 12(1), 7-19. http://doi.org/10.1177/1932296817738791

Zick, G., Elke, G., Becher, T., Schädler, D., Pulletz, S., Freitag-Wolf, S., ... Frerichs, I. (2013). Effect of PEEP and Tidal Volume on Ventilation Distribution and End-Expiratory Lung Volume: A Prospective Experimental Animal and Pilot Clinical Study. PLOS ONE, 8(8). http://doi.org/10.1371/journal.pone.0072675 